\title{
Review of technology: thermochemical energy storage for concentrated solar power plants
}

\author{
Cristina Prieto $^{1}$, Patrick Cooper ${ }^{1}$, A. Inés Fernández ${ }^{2}$, Luisa F. Cabeza ${ }^{3, *}$ \\ ${ }^{1}$ Abengoa Research. C/Energía Solar 1,41012, Seville \\ Spain. Tel.: +34954937111 \\ ${ }^{2}$ Department of Materials Science \& Metallurgical Engineering, Universitat de Barcelona, Martí i \\ Franqués 1-11, 08028 Barcelona, Spain \\ ${ }^{3}$ GREA Innovació Concurrent, Universitat de Lleida, Edifici CREA, Pere de Cabrera s/n, 25001 Lleida, \\ Spain. Tel.: +34.973.00.35.76 \\ *1cabeza@diei.udl.cat
}

\begin{abstract}
To be able to extend the operation of a solar power plant (CSP) up to 15 hours, thermal energy storage (TES) is necessary. But TES also provides more versatility to the plant and makes its reliance during operation hours more dependable. On the other hand, due to the different CSP configurations, a broad spectrum of storage technologies, materials and methods are needed. Sensible and latent heat storage are known technologies in CSP, but thermochemical storage (TCS) is still very much at laboratory level. Nevertheless, TCS has de advantage of nearly no losses during storage and very good volumetric energy density. This review summarizes and compares the different TCS that are today being investigated. Those systems are based in three redox reactions, sulfur-based cycles, metal oxide reduction-oxidation cycles, and perovskitetype hydrogen production, and metal oxide non-redox cycles due to their similarity. This review shows that all these cycles are promising, but none of them seems to have all the characteristics necessary to become the only one storage system for CSP. The main conclusion of the review is that the calcium carbonate is the cycle with most experimentation behind it to infer that it could be viable and should thus be attempted at a research plant scale once a reactivation cycle can be designed; and the manganese oxide cycle, while less developed, is fundamental enough to be a suitable application for desert climates over the rest of the water-frugal or even water-avoiding cycles.
\end{abstract}

\section{Key-words}

Thermal Energy Storage, Thermochemical Energy Storage, Sulfur-based cycles, Metal Oxide Cycles, REDOX reactions, Perovskite 


\section{Introduction}

The added hours of operation and competitiveness needed boosted solar power installations to incorporate thermal storage units, which became ubiquitous in any new concentration solar plant project. The need to extend the operation of the plant by two, four, or even 15 hours (such as in the Gemasolar installation near Granada, Spain; or Cerro Dominador installation to be built in Chile) not only makes the plant more versatile to comply with unexpected demand peaks during night time, where no power is being produced, it also makes its reliance during operating hours much more dependable: stored energy can keep output steady during transition periods such as a cloud pass or dangerous winds [1].

There are two more known types of TES system, sensible storage system and latent storage system. These systems are based on the increment of temperatures in the material by the effect of the energy transfer in the case of sensible system; or based on the heat of fusion or vaporization during the phase change of the storage medium (solid to liquid or liquid to gas). The third thermal energy system is based on the use of the heat reaction in a reversible chemical reaction [2].

In contemporary industrial practices, thermal storage units have been greatly limited to sensible heat technology: using high thermal capacity materials like sand, molten nitrate salts, or saturated steam, to retain heat for differing amounts of time depending on the material. Steam accumulators, which store saturated steam at high pressures of 50 bar (such as in the PS10 tower in Sanlúcar la Mayor, Spain), can provide 20 minutes of extra power at full capacity [3]. Salt towers, having a much higher specific heat capacity, can retain heat for a longer period and dispense it efficiently. In Gemasolar or Cerro Dominador, as mentioned before, this means that they can theoretically operate uninterrupted by using solar power during the day and the stored surplus energy, kept in the molten salts, through the night. Due to diversified demand profiles (with respect to type, amount, and power of needed energy), each energy storage (electrical, thermal, mechanical or chemical storage) requires a specific, optimal solution regarding efficiency and economics.

For thermal energy storage systems it can be derived that there is more than one storage technology needed to meet different applications. Consequently, a broad spectrum of storage technologies, materials and methods are needed. The overall target in designing TES systems is the reduction of investment cost, the enhancement of efficiency, and reliability of the energy supply from it. To achieve these objectives, material, design and system integration aspects have to be considered in equal measure. 
The assessment of identification and selection of the optimal TES system should not only be focused on the storage material, further important components of the power plant also have to be included in this study: the containment, and mainly the heat exchanger and structural parts for charging and discharging, and other devices and sub-components, which are needed for operation and integration such as pumps, valves, control devices, etc.

The most used key indicator in the design of a thermal energy storage system is its thermal capacity; however, selection of the appropriate system depends on many cost-benefit considerations, technical criteria and environmental criteria [4,5]:

- Cost: the storage material itself, the heat exchanger for charging and discharging the system, and the cost of the space and/or enclosure for the TES.

- Technical point of view: high energy density in the storage material (storage capacity); good heat transfer between heat transfer fluid (HTF) and the storage medium (efficiency); mechanical and chemical stability of storage material (must support several charging/discharging cycles); compatibility between HTF, heat exchanger and/or storage medium (safety); complete reversibility of a number of charging/discharging cycles (lifetime); low thermal losses; ease of control.

- Technology: operation strategy; maximum load; nominal temperature and specific enthalpy drop in load; integration into the power plant.

- $\quad$ Power of the cycle and hours number of TES requested.

- Efficiency of the power plant, thus this study should include the assessment of the solar field efficiency and cycle efficiency.

- Investment cost of the solar field and of the storage system and as well as an estimation of O\&M cost of the overall plant.

- Assessment of the trend of the HTF cost and of the material storage cost in the market.

It is very important to have knowledge of the different technologies existing in order to select the optimum storage in each plant and new developments are been carried out in order to optimize the existing design.

Commercial thermal energy can be stored at temperatures from $-40^{\circ} \mathrm{C}$ to more than $565^{\circ} \mathrm{C}$ as sensible heat, latent heat and chemical energy. Thermal energy storage in the form of sensible heat is based on the specific heat of a storage medium, which is usually kept in storage tanks with high thermal insulation. The most popular and commercial heat storage medium is water, which has a number of residential and industrial applications. Underground storage of sensible heat in both liquid and solid media is also used for typically large-scale applications. However, 
TES systems based on sensible heat storage offer a storage capacity that is limited by the specific heat of the storage medium. Phase change materials (PCMs) can offer a higher storage capacity that is associated with the latent heat of the phase change. PCMs also enable a targetoriented discharging temperature that is set by the constant temperature of the phase change. Thermo-chemical storage (TCS) can offer even higher storage capacities. Thermo-chemical reactions (e.g. ad/absorption or the adhesion of a substance to the surface of another solid or liquid, or and chemical reactions) can be used to accumulate and discharge heat and cold on demand (also regulating humidity) in a variety of applications using different chemical reactants [6].

TCS development is still in a fundamental, laboratory stage and far from any proven design and material to be transferred to a commercial scale. However, TCS is being intensively studied because it is a nearly lossless way of storing energy when the chemical reaction partners are stored separately and because it could provide outstanding values of volumetric energy density [7]. Gas-solid reversible reactions are especially suitable for heat storage because of the easy separation of the released gas during the heat absorption. Various kinds of gas-solid reaction systems are under investigation: dehydrogenation of metal hydrides $\left(80-400^{\circ} \mathrm{C}\right)$, dehydration of metal hydroxides $\left(250-800^{\circ} \mathrm{C}\right)$, decarboxylation of metal carbonates $\left(100-950^{\circ} \mathrm{C}\right)$, and thermal desoxygenation of metal oxides $\left(600-1000^{\circ} \mathrm{C}\right)$. Although the enthalpy of reaction is usually extremely high (400-1100 $\mathrm{kWh} \cdot \mathrm{m}^{-3}$ depending on the temperature), feasible energy density is between 200 and $500 \mathrm{kWh} \cdot \mathrm{m}^{-3}$. The reasons for this are mainly twofold: first, the solid must be in powder or pellets; second, the reactants (solid and gas) must be stored in separate tanks in most of the cases (closed systems). A classification of the reactions studied in the last decades is presented in the Figure 1.

In the FP7 of the EU, the projects TCS-Power (2011-2015) [8] and RESTRUCTURE (20112014) [9] are studying $\mathrm{CaO} / \mathrm{H}_{2} \mathrm{O}$ reactions and open redox cycles. The heat storage systems based on metal hydroxides, in which water (steam) reacts with a metal oxide (e.g. $\mathrm{CaO}$ ), are especially interesting for steam power generations applications. However, several problems (e.g. tendency towards agglomeration of the solid, poor heat transport characteristics, low reaction kinetics, possible crystallization after dehydration, and sintering at high temperature) have been pointed out and remain unsolved for most of them. Although we think that the key of TCS are in the control of the kinetics of the reversible reactions or in the reactor wherein said reaction takes place, it is necessary to be aware of all chemical and engineering aspects associated with this system. A state of the art of the main thermochemical cycles has been conducted in this article from a global vision to give the overall approach needed for the study of thermochemical systems. 


\section{Current Thermochemical Storage Technologies}

Together with sensible heat storage and latent heat storage, a third method of storing the thermal energy from solar power is being considered which employs the chemical properties of materials instead of their physical ones. This new path stores the energy produced in the form of potential chemical energy: it is kept in the chemical bonds of the molecules involved in a cycle of reactions in which they are reformed and decomposed whenever the system is being charged or discharged. Thermochemical storage, as it has been called, presents a substantially high storage density, which accommodates plant space constrictions, and a loss-free and long term storage option.

Unfortunately, due to being in its infancy, the technology still presents several questions in terms of its cyclic stability and how easy it is to integrate it with concentration solar power. It shows promise: thermochemical storage is applicable in a wide range of temperatures, from $50^{\circ} \mathrm{C}$ to over $1000^{\circ} \mathrm{C}$, temperatures at which sensible and latent heat would waste copious amounts energy in the form of radiation. It also means that it could be possible to integrate thermochemical storage efficiently with solar tower receptors which can achieve very high temperatures of $1300-1500^{\circ} \mathrm{C}$.

Currently, numerous reactions are being tested to determine their applicability as thermochemical storage materials. These must all comply with some necessary characteristics: the reactions must be completely reversible, must take place at over $500^{\circ} \mathrm{C}$, and the reactants should be easy and cheap to store [10]. This state of the art will focus on three types of Redox reactions which aim to fit these criteria and have been submitted to various stages of testing with a plan to develop them into commercial storage cycles in the future, and includes metal oxide non-redox reactions due to the similarity in the cycle. The reactions investigated are:
1) Sulfur-based cycles
2) Metal Oxide Cycles
3) Perovskite-Type Hydrogen Production

To further maximize the efficiency of any storage cycle, the system should aim at using the solar heat directly to drive the reaction instead of using the heat from a heat transfer fluid. An ideal storage system, then, incorporates a reactor directly on the solar receptors. 


\section{Sulfur Based Cycles}

\subsection{Introduction}

Sulfuric acid is a cheap, commercially available and an extensively researched chemical for which storage is stable, uncomplicated, and makes use of already established technologies. It presents an ideal candidate for modelling a storage cycle around it.

This cycle has drawn heavily from partnerships with the German Aerospace Centre (DLR) who have already experimented heavily on the solar decomposition of sulfuric acid. The DLR cycle, however, was applied to hydrogen gas generation schemes which will be detailed further along.

A novel approach, pioneered by the Californian company General Atomics, modifies the cycle to yield elemental sulfur as a by-product which is then stored and later used as a combustible to generate power (Figure 2). This project, called "Baseload CSP Generation Integrated with Sulfur-Based Thermochemical Heat Storage," is being funded by the United States Department of Energy under their SunShot Initiative [11,12]: a project which hopes to make solar energy, as well as processes derived from solar power, cost-competitive.

\subsection{Reaction Background}

\subsubsection{Charging - Evaporation, Decomposition and Disproportionation}

The reaction uses solar thermal energy at high temperatures to decompose sulfuric acid into water and sulfur trioxide in a solar reactor called an evaporator. It then further dissociates the sulfur trioxide into more water, sulfur dioxide, and oxygen gas in another solar reactor: a decomposer (Figure 3). It operates at much higher temperatures but it is physically placed next to the evaporator to diminish mass transport complications.

The sulfur dioxide then undergoes a disproportionation reaction in a separate reactor vessel at much lower temperatures. Here it reacts with water to re-yield highly diluted sulfuric acid, and liquid, elemental sulfur [12]. These products can be easily stored at ambient conditions after the sulfur cools and solidifies, and the sulfuric acid is concentrated by boiling out the water. 


\subsubsection{Discharging - Combustion}

When the energy is needed, the elemental sulfur is combusted with air to produce sulfur dioxide. The products exit as a superheated gases at very high temperatures where they exchange heat with a Rankine cycle.

Further designs to consider involve the installation of a cogeneration unit using the sulfur dioxide directly to drive a turbine before the Rankine cycle is initiated.

The sulfur dioxide is then reintroduced into the reaction vessel to mix with the sulfur dioxide from the decomposer reactor and with a fresh water feed in order to produce sulfuric acid and start the cycle again.

\subsection{Reaction Steps}

\subsubsection{Sulfuric acid $\left(\mathrm{H}_{2} \mathrm{SO}_{4}\right)$ decomposition}

The HyCycleS project, undertaken at the German Aerospace Centre's (DLR) Köln facility, has tested this method using the aforementioned two-reactor approach [13]. In their arrangement, sunlight is concentrated between 400 and $500^{\circ} \mathrm{C}$ onto the reactor evaporator unit for this step. The temperature is kept relatively low compared to the full capacity of concentrated sunlight so as to reduce the absorber temperature and reduce heat losses due to re-radiation. As a result, the thermal efficiency rises.

The reaction proceeds as follows:

$$
\mathrm{H}_{2} \mathrm{SO}_{4(\mathrm{aq})}+\Delta \mathrm{H}_{\mathrm{rxn}} \rightarrow \mathrm{H}_{2} \mathrm{O}_{(\mathrm{g})}+\mathrm{SO}_{3(\mathrm{~g})} \Delta \mathrm{H}_{\mathrm{rxn}}=+271.8 \mathrm{~kJ} \mathrm{~mol}^{-1} \text { (Equation 1) }
$$

The enthalpy of reaction is highly endothermic so it will need to absorb solar heat for the acid to decompose. This reaction is catalysed on a siliconised silicon carbide ( $\mathrm{SiSiC}$ ) foam impregnated with copper pyrovanadate $\left(\mathrm{Cu}_{2} \mathrm{~V}_{2} \mathrm{O}_{7}\right)$ which serves as the catalyst. Siliconised Silicon Carbide has been selected due to its resistance to high temperatures, corrosion from sulfur oxides, and malleability which makes it easy to work with and also highly resistant to the intense solar flux it will be exposed to [14]. Traditionally, the catalyst employed was platinum, but due to the high costs of such a precious metal, research into other catalysts found that much cheaper copper pyrovanadate is able to work just as well. 
To initiate the reaction, sulfuric acid concentrated at 94 wt.\% is injected into the foam and vaporizes. $\mathrm{H}_{2} \mathrm{SO}_{4}$ then decomposes into $\mathrm{SO}_{3}$ and $\mathrm{H}_{2} \mathrm{O}$.

\subsubsection{Sulfur trioxide decomposition $\left(\mathrm{SO}_{3}\right)$}

The newly formed $\mathrm{SO}_{3}$ and $\mathrm{H}_{2} \mathrm{O}$ exit the first solar reactor and are then released into the second reactor: the decomposer: named so because its role is to further decompose $\mathrm{SO}_{3}$ into sulfur dioxide $\left(\mathrm{SO}_{2}\right)$ and oxygen gas.

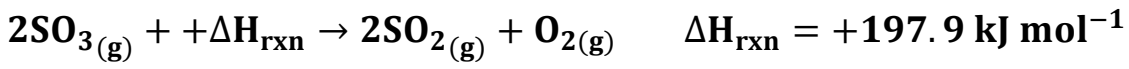

(Equation 2)

This reaction, however, necessitates much higher temperatures $[13,14]$. To this effect, sunlight is concentrated up to an ideal temperature of $850^{\circ} \mathrm{C}$ (Figure 4). Empirical evidence shows that it is possible to run the reaction successfully starting at $650^{\circ} \mathrm{C}$ but the yields are optimized at $850^{\circ} \mathrm{C}$ (conversions of over $80 \%$ vs. $50 \%$ ) (Figure 5).

The catalyst and array of the second reactor differ slightly from the original one. Acting at higher temperatures calls for another kind of catalyst and a different packed bed. General Atomics has identified chromite $\left(\mathrm{FeCr}_{2} \mathrm{O}_{4}\right)$ as a suitable catalyst and it is laced onto another $\mathrm{SiSiC}$ structure but this time formed into a honeycomb array. Chromite, while technically useful in the evaporator as well, suffers from a heavy loss in efficiency as sulfates can readily form on the catalytic surface at those lower temperatures [15]. Other catalysts which have been explored, iron oxide $\left(\mathrm{Fe}_{2} \mathrm{O}_{3}\right)$ and Cuprospinel $\left(\mathrm{CuFe}_{2} \mathrm{O}_{4}\right)$, have proven to lead to a thermal efficiency of $25 \%$ and conversions of over $80 \%$ [16].

This array is kept inside a high-alloy steel reactor sealed with quartz windows. The gases traverse along the length of the honeycomb for which it is worth mentioning that the temperature distribution is not uniform along the array. The areas closer to the quartz are heated up to much higher temperatures than the middle or end of the honeycomb. With increasing operating temperatures the gap between the temperature of the front and back widens: at $650^{\circ} \mathrm{C}$, the front and back differ by little less than $100^{\circ} \mathrm{C}$; when operating at $850^{\circ} \mathrm{C}$ the difference increases to over $200^{\circ} \mathrm{C}$ [15]. Due to a short residence time of 0.5 seconds on average, the average temperature of the honeycomb is used for analysis. Under optimized conditions, the conversion of the system can exceed $80 \%$. This figure is greatly diminished if the operating temperatures fall or if the sulfuric acid flow rate is increased below the optimum. 


\subsubsection{Disproportionation of $\mathrm{SO}_{2}$}

The following step of the process involves the formation of the storage products, elemental sulfur $(\mathrm{S})$ and sulfuric acid $\left(\mathrm{H}_{2} \mathrm{SO}_{4}\right)$ via the disproportionation of sulfur dioxide:

$$
2 \mathrm{H}_{2} \mathrm{O}_{(\mathrm{g})}+3 \mathrm{SO}_{2(\mathrm{~g})} \rightarrow 2 \mathrm{H}_{2} \mathrm{SO}_{4(\mathrm{aq})}+\mathrm{S}_{(\mathrm{l})}+\Delta \mathrm{H}_{\mathrm{rxn}} \quad \Delta \mathrm{H}_{\mathrm{rxn}}=-442.6 \mathrm{~kJ} \mathrm{~mol}^{-1}
$$

(Equation 3)

This reaction, being highly exothermic, will be favored at low temperatures so the reactor is kept between $50^{\circ} \mathrm{C}$ and $200^{\circ} \mathrm{C}$ : notwithstanding, latest models have identified an optimal range between $120^{\circ} \mathrm{C}$ and $150^{\circ} \mathrm{C}$ [12]. At this temperature of operation, however, empirical data for this reaction is difficult to come by because common $\mathrm{SO}_{2}$ disproportionation reactions take place at much reduced temperatures. Forcibly, then, any design fundamentals must be made through modelling.

The optimization of this process is based around two principal targets: maximizing the concentration of sulfuric acid, and maximizing the disproportionation rate of $\mathrm{SO}_{2}$. Both aim to minimize the volume of the system and the quantity of water needed both as a reactant and as a diluent: to concentrate the sulfuric acid before the next cycle, this water will have to be evaporated which will siphon off some of the energy stored. To reach these targets, the system properties must be properly taken advantage of.

Due to the products being liquids formed from gases, they will be favored by higher pressures in accordance to Le Chatelier's principle. Simulations show that the disproportionation rate increases predictably with pressure up to $30 \mathrm{bar}$, at which point it stops presenting significant changes [15]. Albeit, modelling tends to ignore many of the physical interactions which occur in the reactor vessel. The conversion rate will suffer at higher pressures because of $\mathrm{SO}_{2}$ dissolving in the sulfuric acid: dissolved $\mathrm{SO}_{2}$ will not disproportionate. In addition, by dissolving or consuming the $\mathrm{SO}_{2}$ present, the pressure of the system drops as the reaction proceeds, given that $\mathrm{SO}_{2}$ is the largest contributor to the system pressure; this is contrary to the modelling parameters which assume a constant system pressure. This explains why experimental results have yielded data slightly lower than the theoretical models. Current operation conditions oscillate around 15 bar [15].

A second parameter to consider when optimizing the system is the flow rate ratio between water and sulfur dioxide. The stoichiometric ratio of 2:3 does not prove sufficient and feeding water in excess has been shown to increase the disproportionation ratios. The magnitude of the excess 
must be carefully selected for too much water can reduce the activity of $\mathrm{SO}_{2}$, lowering disproportionation rates [17], and too little will make activity of $\mathrm{H}_{2} \mathrm{SO}_{4}$ too high for disproportionation as well as becoming a stoichiometric limitation. Modelling has recommended a ratio of $2 \mathrm{H}_{2} \mathrm{O}: \mathrm{SO}_{2}$.

\subsubsection{Disproportionation reactor operation}

The active volume of the reactor is taken to be the volume of the aqueous phase and it is ruled by the level controllers which regulate the outflow of molten sulfur, from the bottom, and the aqueous sulfuric acid.

The temperature must also be monitored closely with respect to the utilities which are used to influence them. Even though the disproportionation reaction is exothermic, and will thus require a cooling duty during operation, some heat must be supplied during the start-up phase to overcome the unfavorable kinetics which results from working in an aqueous environment.

It is customary and recommendable to operate several reactors in series and decreasing the temperature in each successive reactor [15] (Figure 6). This is done in order to shift the equilibrium towards a higher production of $\mathrm{H}_{2} \mathrm{SO}_{4}$ taking advantage of the tendency of exothermic reactions to be favored by lower temperatures.

Finally, having stated that the principal actor in the pressure of the system is the sulfur dioxide, the operating pressure is similarly controlled by regulating the flow rate of liquid sulfur dioxide into each reactor. Given that the reactors are filled from the first one, the first reactor should operate at the maximum allowable working pressure in order to ensure a pressure gradient along the subsequent reactors.

\subsection{Preparation for storage}

The thermochemical storage options have the advantage of allegedly having an increased shelf time with respect to other thermal storage methods which degrade over time. In the case of a sulfuric acid cycle, the storage materials are the concentrated sulfuric acid, which is fed to the solar reactor, and the solid, elemental sulfur. Both of these coexist with liquid sulfur dioxide so it is important to specify how these are separated.

First, sulfuric acid will be produced within a medium of excess water. Not only is water a product of the decomposition of $\mathrm{H}_{2} \mathrm{SO}_{4}$ in the solar reactor, it is also a reactant for the 
disproportionation of $\mathrm{SO}_{2}$. What this signifies is that the sulfuric acid resulting from these reactions will be diluted. Theoretical data places the maximum thermodynamically attainable concentration at $63 \%$. Empirical data, accounting for system pressure losses and $\mathrm{SO}_{2}$ dissolution in the acid, places this value at a high of $61 \%$. This sets its density at around $1500 \mathrm{~kg} \mathrm{~m}^{-3}$ [18]. When compared to the density values for elemental molten sulfur and liquid sulfur dioxide, 1800 and $1400 \mathrm{~kg} \mathrm{~m}^{-3}$ [19] (rounded estimates given to include variations due to the high pressure and temperatures), it is easy to see that elemental sulfur is quite denser than the rest and will henceforth sink to the bottom of the reactor. This allows it to be extracted in a decanter fashion.

The molten sulfur can then be allowed to cool and crystallize at atmospheric conditions. While the sulfur will not react as a consequence of outdoor storage, it is recommended to shield it from the environment in the interest of preventing moisture to accumulate which can hamper the combustion of the sulfur. In addition, indoor storage can prove safer: the brittle nature of sulfur crystals means that winds can carry sulfur particles around giving an airborne pollutant as well as a combustible if it encounters an open flame.

Any unreacted sulfur dioxide will evaporate together with the water as the concentration of sulfuric acid is increased, via evaporation of the more volatile $\mathrm{H}_{2} \mathrm{O}$, so as to raise its concentration from the $61-63 \%$ in the reactor to the $94 \%$ [14] with which it enters the solar reactor. Obviously this is a heat intensive step and the utilities to drive the boiler can either be rerouted from the sulfur combustion process, using the heat evolved from disproportionation, or incorporated via pre-existing hot utility options in the plant.

\subsection{Electricity generation}

In this cycle, the energy is produced by using the flue gases from the combustion of elemental sulfur as the actuators of the gas turbine. By burning the sulfur at temperatures around $1200^{\circ} \mathrm{C}$, sulfur dioxide is directly produced at elevated temperatures.

$$
\mathrm{S}_{(\mathrm{s})}+\mathrm{O}_{2(\mathrm{~g})} \rightarrow \mathrm{SO}_{2(\mathrm{~g})+} \Delta \mathrm{H}_{\mathrm{rxn}} \quad \Delta \mathrm{H}_{\mathrm{rxn}}=-296.8 \mathrm{~kJ} \mathrm{kmol}^{-1}
$$

(Equation 4)

Due to these temperatures, the $1-5 \%$ of gas that is sulfur trioxide is further converted to sulfur dioxide: 


$$
\begin{array}{ll}
2 \mathrm{~S}_{(\mathrm{s})}+3 \mathrm{O}_{2(\mathrm{~g})} \rightarrow 2 \mathrm{SO}_{3(\mathrm{~g})+} \Delta \mathrm{H}_{\mathrm{rxn}} & \Delta \mathrm{H}_{\mathrm{rxn}}=-791.4 \mathrm{~kJ} \mathrm{kmol}^{-1} \\
\mathrm{SO}_{3(\mathrm{~g})}+\Delta \mathrm{H}_{\mathrm{rxn}} \rightarrow \mathrm{SO}_{2(\mathrm{~g})}+\frac{1}{2} \mathrm{O}_{(\mathrm{g})} & \Delta \mathrm{H}_{\mathrm{rxn}}=+98.9 \mathrm{~kJ} \mathrm{kmol}^{-1}
\end{array}
$$

with the heat for $\mathrm{SO}_{2}$ formation being provided by the environment temperature.

Depending on whether the combustion process uses air or pure oxygen as a reactant, this final gas mixture of sulfur dioxide, and either air or oxygen, then proceeds to actuate the turbine. The two common ways in which it does so are detailed following.

\subsubsection{Indirect generation}

This method gets its name because the flue gas itself does not actuate the turbine. It superheats an air feed via a heat exchanger which works the turbine. The energy-spent flue gas is sent back into the reactor to disproportionate. The flow rate at which it is being sent back into the reactor must be controlled so that the pressure in the initial reactor never rises above the maximum operating pressure (Figure 2).

\subsubsection{Direct \& indirect combined cycle generation}

This method employs two distinct turbines. The first one is actuated by the flue gas as it leaves the combustion chamber. This stream then is passed through a heat exchanger in contact with a water cycle which it causes to boil and spin a second turbine, thus powering a Rankine cycle (Figure 7). The rest of the gas, including mostly unreacted air/oxygen gas as well as sulfur trioxide, is sent to the $\mathrm{H}_{2} \mathrm{SO}_{4}$ concentrator to reincorporate into the cycle. In certain cases, when $\mathrm{SO}_{2}$ flows from the solar reactor are quite low, the $\mathrm{SO}_{2}$ and other flue gases emanating from the first turbine can be pumped back into the disproportionation reactor to keep the pressures and operating conditions steady. Power is still being generated by the first turbine. This is the current cycle General Atomics plans to develop [12]. The more complex construction and larger capital costs are offset, allegedly, by substantial power gains.

\subsection{Variations to the cycle}

The sulfuric acid has proven to be an efficient and usable cycle for storing solar energy. Nonetheless, when power is not the only desired product, the cycle can be adapted to become a regenerating intermediate in a production chain. The most widespread application, both in terms of a research and production, is the production of hydrogen gas. Two cycles have been 
substantially developed to this end: the Westinghouse cycle, incorporating electrolysis, and the sulfur-iodine cycle using iodine as an intermediate as well as performing the role of a catalyst.

\subsubsection{Westinghouse Cycle}

The difference between the original sulfur cycle and the Westinghouse variation, also known as the Hybrid Sulfur cycle, is the way in which the sulfuric acid is regenerated (Figure 8). Sulfur dioxide and water, formed in the solar reactor from the decomposition of sulfuric acid (just like in the first method) is submitted to a large current in order to electrolyze it [20]. The process can take place because, unlike the previous method, $\mathrm{SO}_{2}$ dissolved in water is favored in this instance. When the gas is hydrolyzed together with water it yields sulfuric acid and the product: hydrogen gas:

$$
2 \mathrm{H}_{2} \mathrm{O}_{(\mathrm{l})}+\mathrm{SO}_{2_{(\mathrm{g})}}+\Delta \mathrm{H}_{\mathrm{rxn}} \rightarrow \mathrm{H}_{2} \mathrm{SO}_{4_{(\mathrm{aq})}}+\mathrm{H}_{2}(\mathrm{~g}) \quad \Delta \mathrm{H}_{\mathrm{rxn}}=+40.8 \mathrm{~kJ} \mathrm{kmol}^{-1}
$$

(Equation 7)

Electrolysis reactions, being endothermic, rely on the energy supplied by the electric current hydrolyzing the solution. Sulfuric acid is collected at the anode and hydrogen gas at the cathode.

The cycle continues with the gas collection of the hydrogen gas and the concentration of the sulfuric acid. This cycle can run continuously, if hydrogen gas is the desired product, or the hydrogen can be stored and combusted, much like the sulfur was in the first method, to power a turbine generator when the system is to be discharged.

While this system is easier to separate, considering the liquid phase will only be composed of water and sulfuric acid, and the gas product is purely hydrogen gas, the compromise is that the plant must store hydrogen gas instead of sulfur. This becomes a safety concern because hydrogen is much harder to contain: it is invisible and inodorous and combusts violently. While the system itself is less complex, due to bypassing the liquid-liquid separation necessary for elemental sulfur, the storage becomes more hazardous and costly.

The final efficiency for the system resulted in $42 \%$ but this required the sulfuric acid concentration to rise to $65 \%$, instead of the $61 \%$ empirically achieved. Nonetheless, the system has been predicted to increase its efficiency by $6 \%$ if the electrolysis is carried out in multiple stages, which incurs larger capital costs [21]. 
Models of this type of storage cycle have been run successfully at the German Aerospace Centre (DLR) pilot plant in Jülisch, Germany.

\subsubsection{Sulfur-iodine cycle}

This cycle, producing oxygen and hydrogen gas as its by-products, relies on a system in which the excess of $\mathrm{H}_{2} \mathrm{O}$ results in the reactions proceeding spontaneously (Figure 9). At its core it is based around the Bunsen reaction:

$$
\begin{array}{r}
\mathrm{I}_{2(\mathrm{aq})}+2 \mathrm{H}_{2} \mathrm{O}_{(\mathrm{l})}+\mathrm{SO}_{2}(\mathrm{~g}) \\
\rightarrow \mathrm{H}_{2} \mathrm{SO}_{4(\mathrm{aq})}+2 \mathrm{HI}_{(\mathrm{g})}+\Delta \mathrm{H}_{\mathrm{rxn}} \quad \Delta \mathrm{H}_{\mathrm{rxn}}= \\
-128 \mathrm{~kJ} \mathrm{kmol}^{-1} \quad \text { (Equation 8) }
\end{array}
$$

This highly exothermic reaction favors lower temperatures so it tends to be run at $120^{\circ} \mathrm{C}$. The sulfur and iodine will be recycled in the system cyclically so both substances need to return to their original form. Sulfuric acid, as seen in the previous methods, will be decomposed to sulfur dioxide in a solar reactor. Hydroiodic acid, HI, will recombine into its iodine original state under intense radiation in the following endothermic reaction:

$$
2 \mathrm{HI}_{(\mathrm{g})}+\Delta \mathrm{H}_{\mathrm{rxn}} \rightarrow \mathrm{H}_{2(\mathrm{~g})}+\mathrm{I}_{2(\mathrm{~g})} \quad \Delta \mathrm{H}_{\mathrm{rxn}}=+9.4 \mathrm{~kJ} \mathrm{kmol}^{-1}
$$

(Equation 9)

$\mathrm{HI}$ is decomposed at $450^{\circ} \mathrm{C}$ [22]. The hydrogen gas is collected and separated from any leftover HI gases via a membrane. The iodine is recycled into the main reactor where it participates in subsequent Bunsen reactions.

Like the last process, the hydrogen gas here can be produced continuously or stored to run a Rankine or Brayton cycle in the case that this S-I cycle is complementing a solar power plant.

This reaction, pioneered by the Californian company General Atomics, has been tested in the Hydrogen Production by Thermochemical Cycles project (HYTHEC) [24] which involved a joint venture between 6 partners from 5 different European Union nations. The reactor soaks an small $\mathrm{SiSiC}$ foam with the acid which is suspended before a larger porous structure. The acid is evaporated in the small foam and reacts as it traverses the porous structure through to the exhaust.

Smaller scale experiments have been carried out using Bromine as the halogen since the chemistry is very similar [25]. 


\subsection{Safety considerations}

As mentioned previously, this system has substantial health benefits when it comes to the storage. Sulfur and sulfuric acid do not require temperature-controlled environments or pressurized vessels. Elemental sulfur is of very low toxicity but, if absorbed by contact with the eyes or the skin, it can cause irritation if one is exposed to a high dose [26]. This becomes a risk for the operators of the sulfur storage or any nearby populations which could be exposed to the brittle sulfur powder through wind upheavals.

Sulfuric acid will only decompose at temperatures above $300^{\circ} \mathrm{C}$ so there is little danger of natural decomposition; henceforth, it can also be stored at ambient conditions. Nonetheless, this storage poses substantially more damage. Sulfuric acid for this system is planned to be stored at $94 \%$ concentration in order for it to be ready on-demand to enter the solar reactor. At $94 \%$ concentration, sulfuric acid is highly reactive and corrosive, posing considerable damage to metal structures; it also incurs a high dehydration potential which can cause severe burns on materials and skin tissue. Operators must wear proper protective equipment and the acid must be maintained within the storage vessel or pipework at all times.

The inner cycle of the system is a closed loop so there should be little hazard from the materials inside aside from unintended leaks. In this case there is a high danger of inhaling toxic fumes like sulfur dioxide and trioxide which are extremely pernicious. Sulfur dioxide will be detectable due to its distinct odor but enough exposure might cause breathing difficulties and birth defects if the contact is chronic. Sulfur trioxide is much more noxious and will cause immediate severe burns when inhaled, mainly due to its tendency to extract water from its surroundings and form sulfuric acid.

\subsection{Conclusions}

The sulfur cycle has not been tested commercially yet but its simplicity and efficiency in storing energy, in the form of non-degradable chemical bonds, has launched large scale research initiatives. The system is quite versatile in terms of catalysts, storage materials (sulfur, hydrogen), and even the chemistry of the cycles used to produce them (electrolysis, disproportionation, halogen reactions). This technology, much like solar energy, seems to be evolving into an option to be tailored to the necessities and facilities of each storage system it is attached to, instead of acting as an overarching, ubiquitous method. 
Future developments still to be undertaken to ensure the proliferation of this technology will revolve around: preparing the Brayton cycles to run under the harsh and corrosive conditions of sulfur dioxide and trioxide; maximizing the selectivity in the sulfuric acid generation steps; increase the conversion in each step so as to reduce sizes and utility costs; and maximizing the flow rates through the reactor without punishing its performance.

\section{Metal Oxide $\left(\mathrm{M}_{\mathrm{x}} \mathrm{O}_{\mathrm{y}}\right)$ Cycles}

\subsection{Introduction}

Manganese and calcium oxides undergo oxidation with air at high temperatures provided by solar radiation. In this respect their operation does not differ from other transition metal oxides; yet, they are singled out, alongside cobalt oxides, as some of the most promising.

Once again, General Atomics and the German Aerospace Centre have partnered in order to test these oxides, along other transition metal oxides, in terms of their applicability as storage materials. The chemistry for these reactions already has extensive research due to their widespread use and availability.

For a metal oxide to be a suitable candidate for a thermochemical energy storage cycle, it must be able to withstand multiple thermal charge and discharge cycles with minimal degradation. In terms of chemistry: it must be able to oxidize, reduce, and re-oxidize without much loss or resistance. Furthermore, to remain competitive, the raw material cost of the oxides must be low enough for the energy source to remain competitive and the operating cost parameters, like temperature of reaction, must be readily attainable; finally, the system should have a large energy density for it to function effectively as an energy storage alternative. To analyze the potential of manganese and calcium oxides they will be compared with the goals that the United States Department of Energy has established as its storage goals for 2015: an efficiency of 93\%, a cost per kilowatt-hour of $0.06 \mathrm{USD}$, and operation temperatures above $600^{\circ} \mathrm{C}$ [11].

\subsection{Selecting a Suitable Reaction}

In this state of the art, three reactions will be dissected to assess their capability of successfully integrating into a solar energy storage cycle. 
Calcium, which forms a +2 ion when it reacts, is a common alkali earth metal and is naturally found in limestone $\left(\mathrm{CaCO}_{3}\right)$ and quicklime $(\mathrm{CaO})$ : two materials which are prevalent in today industry, mainly due to their carbon capture properties.

Calcium carbonate, when infused with energy, will decompose into calcium oxide and carbon dioxide. When the temperature of the system dips below a threshold temperature, the reverse reaction will be spontaneous, simplifying the material requirements for the cycle:

$$
\mathrm{CaCO}_{3(\mathrm{~s})}+\Delta \mathrm{H}_{\mathrm{rxn}} \leftrightarrow \mathrm{CO}_{2(\mathrm{~g})}+\mathrm{CaO}_{(s)} \quad \Delta \mathrm{H}_{\mathrm{rxn}}=+178.4 \mathrm{~kJ} \mathrm{kmol}^{-1}
$$

(Equation 10)

Similarly, calcium oxide can be hydrated and will release heat in the process. This process requires only water to start the reaction and heat to dry the calcium hydroxide in order to reverse the process:

$$
\mathrm{CaO}_{(s)}+\mathrm{H}_{2} \mathbf{O}_{(g)} \leftrightarrow \mathrm{Ca}(\mathrm{OH})_{2(s)}+\Delta \mathrm{H}_{\mathrm{rxn}} \quad \Delta \mathrm{H}_{\mathrm{rxn}}=-109.2 \mathrm{~kJ} \mathrm{kmol}^{-1}
$$

Being a transition metal, Manganese forms in several states and so pairs with oxygen in different molecular formulas. Nonetheless, not all of the reactions linking the oxides to each other are viable. Four have been found to be stable at ambient conditions: $\mathrm{MnO}, \mathrm{MnO}_{2}, \mathrm{Mn}_{2} \mathrm{O}_{3}$, and $\mathrm{Mn}_{3} \mathrm{O}_{4}$. The details of the operation conditions to transition from each of these compounds into the other need to be investigated so that the optimal reaction can be deduced:

- $\mathrm{Mn}_{3} \mathrm{O}_{4} \leftrightarrow \mathrm{MnO}$ requires temperatures that are too high for solar reactors $\left(1700^{\circ} \mathrm{C}\right)$.

- $\mathrm{Mn}_{2} \mathrm{O}_{3} \leftrightarrow \mathrm{MnO}_{2}$ requires pure $\mathrm{O}_{2}$ at a similarly unfeasible pressure of 3000 bar due to the formation of a surface barrier that prevents further oxidation.

- $\mathrm{Mn}_{3} \mathrm{O}_{4} \leftrightarrow \mathrm{Mn}_{2} \mathrm{O}_{3}$ did proceed at suitable conditions except the kinetics were very slow [27].

Of these setbacks, the reaction kinetics is the simplest to overcome by the addition of other transition metal oxides as catalysts. Henceforth, the following reaction is chosen for the manganese cycle:

$$
6 \mathrm{Mn}_{2} \mathrm{O}_{3(\mathrm{~s})}+\Delta \mathrm{H}_{\mathrm{rxn}} \leftrightarrow 4 \mathrm{Mn}_{3} \mathrm{O}_{4(\mathrm{~s})}+\mathrm{O}_{2} \quad \Delta \mathrm{H}_{\mathrm{rxn}}=+416 \mathrm{~kJ} \mathrm{kmol}^{-1}
$$

(Equation 12) 


\subsection{Calcium Carbonate $\left(\mathrm{CaCO}_{3}\right)$ Cycle}

The experimental setup for this reactor was simulated in New Zealand by Industrial Research Limited and it bases its plant design on a two-stage process with storage tanks as buffer zones. The basis of their selection of calcium carbonate as the thermochemical storage substance was its energy density and operating temperature $\left(4400 \mathrm{MJ} \mathrm{m}^{-3}\right.$ and $800-900^{\circ} \mathrm{C}$ respectively): the report states that the "thermochemical systems generally require higher temperatures to initiate storage of energy, but conversely provide higher temperatures on the release of that energy" [28]. The high temperatures required by the calcium carbonate loop, if attainable in a solar reactor, will provide a lot more storage upon release and for less space occupied than other storage media.

\subsubsection{Plant Setup}

The plant is composed of two distinct units and buffered by the storage tanks of the products and reactants, all of which are stable under practicable conditions of temperature and pressure (Figure 10) [28]. The first section revolves around the calciner: the solar reactor which converts the calcium carbonate into calcium oxide and carbon dioxide. The second section of the plant is dominated by the carbonator: a mixture of air and carbon dioxide is contacted with calcium oxide to reform calcium carbonate. The storage tanks contain: calcium carbonate and calcium oxide at ambient conditions; and, pressurized carbon dioxide. The plant model is based on a thermal power output of $50 \mathrm{MW}$.

\subsubsection{Charging - Solar calciner}

Whereas this reaction is common in industry, the novelty in this cycle is that the calciner is being powered by solar radiation and not plant-provided heat source. The raw materials in this stage are purely sunlight and the calcium carbonate in powder form to be fed into the reactor. From equation 10 it is evident that, being an endothermic reaction and also owing to its high enthalpy of reaction, this system must take place at an elevated temperature. The reaction has been shown to be spontaneous in the range of $600-900^{\circ} \mathrm{C}$ depending on the gas pressure. In a solar calciner the reaction will only be spontaneous starting from $833^{\circ} \mathrm{C}$. When plant optimization is considered, it is best to run the calciner at $900^{\circ} \mathrm{C}$. Based on a $50 \mathrm{MW}$ of thermal output model, $100 \mathrm{MW}$ would be absorbed by the calciner.

In order to bolster the efficiency of the plant, process integration must recover as much heat as possible from the various streams. Considering that the newly formed $\mathrm{CaO}$ and $\mathrm{CO}_{2}$ won't be 
needed to produce until a transient period or night time, after they are synthesized they will go into their respective buffer storage tanks. This means a significant amount of sensible energy could be wasted unless it is recovered. To do this, the model envisions a solid-solid heat exchanger between the outlet $\mathrm{CaO}$ and $\mathrm{CO}_{2}$ and the inlet $\mathrm{CaCO}_{3}$ coming from storage at ambient conditions. This model assumes a continuous system, which has been difficult to design with solar reactors. Nonetheless, even in a batch setting, using the heat of previous batches to preheat an incoming batch will help to reduce the residence time in the solar reactor. The gas, best stored at 60 bar so that it will be ready to react optimally in the second stage, needs to be compressed from the ambient pressure it is produced at. The heat evolved during the compression can similarly be used to preheat the calcium carbonate.

The gas-solid heat exchanger has an approach temperature of $10^{\circ} \mathrm{C}$ but due to the difficulty of designing an efficient heat exchanger serving two solids, the approach temperature must be doubled to $20^{\circ} \mathrm{C}$.

A rotary solar kiln is used for the calciner, such as the ones modelled by Meier et al. (2005) [29]. Past solar kiln designs have run into difficulties in obtaining high conversions due to the material sliding down the walls and settling as a constant mass at the bottom of the walls. Conversions have, on average, languished at 40-50\% (with $\mathrm{Co}_{3} \mathrm{O}_{4}+5 \% \mathrm{Al}_{2} \mathrm{O}_{3}$ annealed), rising up to $70 \%$ if pure cobalt oxide was used (expensive reactant) [30]. This was especially limiting due to those kilns being modelled operating in a batch setting: the conversion inefficiency would curtail the amount of power being stored.

The Meier kiln (Figure 11), developed by the Paul Scherrer Institute and Swiss Federal Institute of Science and Technology, in Zurich, as well as QualiCal Srl, in Bergamo, solves these limitations by installing absorber tubes which run along the length of the kiln and carry the reactant powder within them. Like previously observed solar reactors, the kiln is composed of silicon carbide. An inlet tube leading into a preheater in the back and an outlet tube close to the window of the kiln make this process continuous. The design has an average calcination degree equal to $98.2 \%$ [29] and can operate within upwards from $1200 \mathrm{~K}$ until $1400 \mathrm{~K}$, potentially improving the thermal efficiency over the original storage cycle.

\subsubsection{Discharging - Carbonator}

The second stage of the plant, the carbonator, is the section which is in effect when the energy needs to be released: during night time operation or a transient period of low or no direct 
sunlight. The process utilizes the heat of carbonation to heat the heat transfer fluid, air, to $875^{\circ} \mathrm{C}$. This high enthalpy air is used to drive a gas turbine to generate the energy required.

To initiate this, the stored $\mathrm{CaO}$ from the calciner is contacted with a mix of air and $\mathrm{CO}_{2}$ to release the heat of carbonation, which is $-178.4 \mathrm{MJ} \mathrm{kmol}^{-1}$ at $20^{\circ} \mathrm{C}$ :

$$
\begin{array}{r}
\mathrm{CO}_{2}+\mathrm{CaO} \leftrightarrow \mathrm{CaCO}_{3}+\Delta \mathrm{H}_{\mathrm{rxn}} \\
\Delta \mathrm{H}_{\mathrm{rxn}}^{2 \mathrm{o}^{\circ} \mathrm{C}}=-178.4 \mathrm{MJ} \mathrm{kmol}^{-1}
\end{array}
$$

(Equation 13)

The design parameters for the carbonator must take into consideration the purpose of the outlet stream, to do work on a gas turbine, as well as the recyclability of the materials. If temperatures are too high, the particles could sinter, limiting their conversion. Also, there is a minimum pressure of $\mathrm{CO}_{2}$ which the carbonator must be under for the carbonation reaction to run: the gas needs to be pressurized in order to reform into a solid.

The last parameter to consider when designing the carbonator is the carbonation efficiency; this also highlights the biggest setback with the calcium carbonate cycle: the recyclability. The carbon activity is defined as the percentage of $\mathrm{CaO}$ that does carbonate [28] and, after 20 cycles, was found to languish below 20\%. Plant optimization recommends an ideal range between 20 and $40 \%$ activity when designing the carbonator: values below $20 \%$ represent a loss of energy density which is no longer superior to using molten salts due to the increased mass flow rates needed for the same amount of energy delivered; values above $40 \%$ do not show a significant throughput increase and so cannot suitably justify the increased capital costs to get to that activity. After process optimization, a model was selected based on a temperature of $875^{\circ} \mathrm{C}$ and an operating pressure of 6.7 bar gauge. The activity which yielded the best plant efficiency was $20 \%$, with $43.7 \%$, but the capital costs of its high solids flow rate was not accounted for so the predicted optimum activity was inferred to be close to $25 \%$ (efficiency $\approx 42.8$ ) [28].

The carbonator itself is simpler to design than the calciner because, since it is not expose to the sun, it draws upon pre-existent modules designed for the production of calcium carbonate. The closest technology is a pressurized fluid bed combustor (PFBC), invented by Foster Wheeler Energia Oy in Finland, which links with an open Brayton cycle, powered by the exit gases from the carbonator.

These carbonator exit streams, calcium carbonate and the air and unreacted carbon dioxide mixture, must exchange heat as well according to the process integration. The exiting calcium 
carbonate preheats the air and carbon dioxide mixture coming from the $\mathrm{CO}_{2}$ storage tank (an air intake downstream from the $\mathrm{CO}_{2}$ reservoir provides the air for the mixture). Calcium carbonate will exit at $875^{\circ} \mathrm{C}$ and will be stored at ambient temperature so by yielding its sensible heat, the air $/ \mathrm{CO}_{2}$ mixture can enter the carbonator at $739^{\circ} \mathrm{C}$, reducing the residence time.

The other exit stream, unreacted $\mathrm{CO}_{2}$ (due to the carbonation activity) and leftover air are run through a gas turbine to produce power. The exit gases drop to $415^{\circ} \mathrm{C}$ from their initial $875^{\circ} \mathrm{C}$ and are then contacted in another gas-solid heat exchanger to preheat the $\mathrm{CaO}$ coming from storage. Carbon dioxide is assumed to never be emitted from the plant because unreacted $\mathrm{CO}_{2}$ will react with the calcium oxide in this step [28], leaving only air as an exhaust at $34^{\circ} \mathrm{C}$. The calcium oxide thus enters the carbonator at $405^{\circ} \mathrm{C}$.

\subsubsection{Further improvements}

The most important consideration for this system is increasing the carbonation activity; due to this limitation, the plant efficiency of $42.8 \%$ is still uncomfortably low for investment. More importantly, if after 20 cycles the activity rests below 19\% and the system is optimized at present with $25 \%$, this means that new $\mathrm{CaO}$ or $\mathrm{CaCO}_{3}$ will have to be inevitably replaced into the system, attributing operating costs to the sourcing of new raw materials. For an ideally closed cycle, this is oxymoronic.

Other methods proposed include: the doping of the calcium oxide, with salts; carbon dioxides shocking; hydration methods which, though proven effective, lead to solid attrition [28]. The most promising of the reactivation methods employ steam. While regenerated activities of 40$60 \%$ have been reported, this adds the trouble of including steam into the system - previously, it worked entirely water-free.

Less urgent design upgrades revolve around the kiln itself. A beam-down system has been suggested in order to reduce the transportation heat losses in the system. The Weizmann institute in Israel is experimenting with this technology but so far the Meier kiln seems to be working sufficiently well to sustain the reaction cycle [31].

\subsection{Calcium hydroxide $\left(\mathrm{Ca}(\mathrm{OH})_{2}\right)$ cycle}

The hydration and dehydration of calcium oxide releases and consumes heat respectively [31]. This storage system relies on the heat evolved, when $\mathrm{CaO}$ is contacted with water, to produce power by indirectly heating a heat transfer fluid (Figure 12). The most advanced prototype for 
industrial storage is being developed by the German Aerospace Centre and while the reactor bed has been modeled experimentally, it has not yet been tested in connectivity to a power block.

The benefits of this cycle are centered on the simplicity of the system and the low cost of the raw materials: only quicklime $(\mathrm{CaO})$ and water are present in the reactor and, theoretically, the water can be recovered and reused. How close the experimental system follows the theory will have to be determined by further testing. One major setback, other than the required water use, is the limitations of throughput: the amount of energy stored is limited by the amount of reactant which reasonably fits in the reactor.

\subsubsection{Plant Setup}

The system is composed of two distinct loops: the reactor vessel and the power loop. These only meet when exchanging heat. An important difference from the other processes is that the $\mathrm{CaO}$ or $\mathrm{Ca}(\mathrm{OH})_{2}$ are not heated directly by solar radiation; instead, the heat transfer fluid operating in the plant exchanges heat directly with reactor and receives heat from the reactor during discharge (Figure 13).

The indirect heating system was selected because it presented a lower pressure drop, given that the HTF would not have to interact with the reactant power; the conditions of the HTF would not influence the reaction itself; and, finally, it was a simpler operation which diminishes the chances of mechanical complications [32].

\subsubsection{Charging - $\mathrm{Ca}(\mathrm{OH})_{2}$ dehydration}

The reaction is initiated when heat is transferred from the plant heat transfer fluid, be that air, steam, or salts, into the solid. The DLR uses nitrogen gas $\left(\mathrm{N}_{2}\right)$ in their lab-scale plant as an inert heat carrying medium, notwithstanding, this early plant was a directly heated system. When transitioning to a larger, $10 \mathrm{~kW}$ plant, the design changed to an indirect heating setup and the HTF now interacts with the solids using air. This exchange happens in a rectangular plate heat exchanger where the reactor gas (steam for discharging) travels the short distance and, in a cross flow arrangement, the HTF is coursed through the long distance. The solids are on the steam side and will release steam which will exit the reactor upwards and out of contact with the solids upon heating by the HTF. It is essential for an efficient operation of the system that the material chosen for the reactor bed has high conductivity. A bed with $20 \mathrm{~W}(\mathrm{~m} \cdot \mathrm{K})^{-1}$ can complete the reaction up to $100 \%$ conversion in close to $20 \mathrm{~min}$ [10]. More conservative estimates have still reported high conversions of $93 \%$ [32]. 
The dehydration of calcium hydroxide will be spontaneous and feasible within the range of 400$600^{\circ} \mathrm{C}$. When optimized, the DLR found an equilibrium temperature of $507^{\circ} \mathrm{C}$ at 1 bar to be best suited. This temperature is provided by air which itself has received its heat from the plant heat transfer fluid. Looking at equation 14, one can see that while the theoretical energy density of this reaction is reported to be close to $833 \mathrm{kWh} \mathrm{m}^{-3}$ [28], when taken to a pilot scale this density drops to the DLR reported value of around $410 \mathrm{kWh} \mathrm{m}^{-3}$. The missing energy is that which is taken by the system as the water produced evaporates. Considering this case, separate experimental investigations have published chemical efficiencies of $46 \%$ for this reaction [34], slightly lower than the $49 \%$ initially estimated for the DLR setup. This loss can be avoided if the water is supplied already in steam form, given that the latent heat to vaporize water is a large section of the total heat supplied - energy released amounts to the full $109.2 \mathrm{~kJ} \mathrm{kmol}^{-1}$ instead of the reduced $73.7 \mathrm{~kJ} \mathrm{kmol}^{-1}$ if water must be vaporized [35].

Previous tests at the DLR have carried the reaction at the higher band of the reaction, $600^{\circ} \mathrm{C}$. This is because calcium oxide $(\mathrm{CaO})$ is able to retain its heat very efficiently. Thus it can not only function as thermochemical heat storage but as a sensible heat source as well.

\subsubsection{Discharging - CaO hydration}

When needed, energy will be released and the same power bloc of the existing plant will be used. The difference arises from where the heat to warm the HTF is originating from: during normal operations it comes from the sun; during off or transient periods it is generated by the $\mathrm{CaO}$ reactor as it is hydrated and reacted into $\mathrm{Ca}(\mathrm{OH})_{2}$ :

$$
\mathrm{CaO}+\mathrm{H}_{2} \mathrm{O} \leftrightarrow \mathrm{Ca}(\mathrm{OH})_{2}+\Delta \mathrm{H}_{\mathrm{rxn}}
$$

(Equation 14)

The reactor and the circulating water are heated up by the release of reaction energy as steam and the calcium oxide interact. Conversions in this step, given enough time and depending on the process temperature and significantly on the mass flow rate of steam, can reach up to $99 \%$ [33].

There are additional reasons as to why it is desirable to keep the calcium heated, as it facilitates the discharge procedure. Schaube et al., from the DLR, report that when designing the steam stream which initiates the discharge: "to achieve a maximum temperature difference between the in- and outlet the pressure should be set so that $\mathrm{T}_{\mathrm{eq}}=\mathrm{T}_{0}$ [33]. That is, the equilibrium temperature and the resting $\mathrm{CaO}$ temperature should be equal. Considering that these 
experiments took the temperature of equilibrium to be $550^{\circ} \mathrm{C}$ at $1.78 \mathrm{bar}$, and contrasting that with the DLR setup at around $510^{\circ} \mathrm{C}$ at ambient pressure, the pressure will have to be increased for the discharge procedures (Figure 14). This operational complication can be justified given that the steam inlet is shown to exit the reactor at very close to the same temperature as the $\mathrm{CaO}$ right before the discharge. What this means is that the discharge will be a high quality steam, at whichever temperature the $\mathrm{CaO}$ started at when the discharge reaction took place - to maximize the steam outlet temperature it is thus important to prevent the $\mathrm{CaO}$ from losing heat: insulation for the reactor becomes paramount.

\subsubsection{Conclusions}

The $\mathrm{CaO} / \mathrm{Ca}(\mathrm{OH})_{2}$ cycle is an attractive system because of its simplicity: it utilizes simple raw materials such as quicklime and water; it can be integrated into the power block by looping a HTF around it; the reaction occurs within one reactor with no transport of solids anywhere; and, finally, the operating temperatures are high enough to be efficient but low enough to be attainable without involving complex mechanical engineering. Calcium hydroxide cycles have, to this effect, even been suggested for trough systems.

The main setbacks with this cycle originate with the water. The use of steam, to be more precise, is problematic for two reasons: first, it requires the addition of water to the system, and second, its recyclability has not been proven.

In theory, this is a closed water cycle and the steam that is introduced during hydration of $\mathrm{CaO}$ will be recovered during dehydration of $\mathrm{Ca}(\mathrm{OH})_{2}$. In practice, though, because the steam will have to be interspersed with air (chosen over nitrogen due to costs), there is a chance that some water might be flushed out of the system whenever the change is made - it opens an avenue for the gas to escape. In the long term, this signifies that water might have to be replaced into the system: a complication for desert systems of which the magnitude will only be clear once the cycle is tested in on a larger scale.

Even if sourcing is not a big issue, the conditions of steam delivery are. As mentioned, to optimize the heat delivery from the discharge, the reaction should be carried out at close to the resting temperature of the calcium oxide. This demands high temperatures from the inlet steam: in Schaube et al. test [33], for a $\mathrm{CaO}$ temperature of $550^{\circ} \mathrm{C}$ and a pressure of 1.78 bar, higher than the reactor analyzed, the required steam was fed at $450^{\circ} \mathrm{C}$. Combined with a limited thermal capacity for the steam to carry, a high volume of steam will have to be preheated with a substantial amount of energy before it is ready to react. This high duty will curtail the efficiency 
of the thermal system: in addition to the HTF energy needed to drive the dehydration, additional energy needs to be transferred to the steam to initiate the same amount of discharge power.

The last factor complicating the adoption of this technology is the unproven cyclability. While Schaube et al. [33] saw no evident decrease in conversion with each successive cycle, only four were performed in that trial. Likewise, the DLR saw no diminished cyclability even when they extended the cycles to eight. A study from 1976 by G. Bauerle [36] tested the cyclability up to 1100 times and found only a $10 \%$ loss in cyclability but the conditions of this test and their resemblance to the reactor setup have not yet been investigated.

\subsection{Manganese Oxide $\left(\mathrm{M}_{\mathrm{x}} \mathrm{O}_{\mathrm{y}}\right)$ Cycle}

\subsubsection{Introduction}

Having previously selected the following reaction as the basis for the manganese oxide system:

$$
6 \mathrm{Mn}_{2} \mathrm{O}_{3}+\Delta \mathrm{H}_{\mathrm{rxn}} \leftrightarrow 4 \mathrm{Mn}_{3} \mathrm{O}_{4}+\mathrm{O}_{2}
$$

\section{(Equation 15)}

The plant needs to be designed paying special considerations as shortcomings are reported: the crippling reaction rate. Further experimentation also showed that it did not re-oxidize as easily after a cycle was complete so special attention was also placed on how to guarantee a full reconversion [17].

It is important to consider why manganese oxides have been considered before other metal oxides. This cycle has been shown to work with bromine oxides but the best performance has been achieved using cobalt oxides which have a storage density of more than 4 times that of the manganese cycle in consideration. The reason why it was discarded was due to cost optimization: manganese can be made to work sufficiently well and at substantially lower costs than a cobalt cycle. The bromine cycle was cheaper than cobalt but also less efficient so it was bypassed with similar criteria.

\subsubsection{Plant Setup}

In first iterations of this system, it was planned for it to be an indirect heat transfer cycle similar to the previous calcium hydroxide heat storage. A factor to be considered about a manganese 
oxide system run in this setup is: the indirect heat transfer meant a much larger approach temperature would be needed or else the materials would take a lot longer to heat up to the design specifications. In a system with a reactant that is known to be slow to react, this was less than ideal. An indirect heating would also mean closing any possibility of a continuous system: the system will only be able to store as much heat as allowed by the materials in the reactor, not those which could also be sourced during operation. In the end the choice was left to operating a fixed bed, such as the reactor for the calcium hydroxide cycle, or a rotary kiln, like the calcium carbonate. Given the fast heat exchange possible through direct irradiation by sunlight, the rotary kiln was chosen to be the optimal reactor for this cycle.

\subsubsection{Selecting the metal oxide}

As established, manganese oxide suffers from unfavorable kinetics and concerns with cyclability: only $6 \%$ could be re-oxidized after the first cycle. As is common when the kinetics of a reaction need to be improved a catalyst is tested.

After testing various compounds, iron oxide $\left(\mathrm{Fe}_{2} \mathrm{O}_{3}\right)$ was tested to work best and it could effectively multiply the amount re-oxidized by almost $17 \%$ (6\% to $100 \%)$. Judging by the trials performed, a $10 \%$ presence of $\mathrm{Fe}_{2} \mathrm{O}_{3}$ within the manganese lattice could guarantee a full reoxidation. The chemical explanation for this relies on the behavior of manganese when submitted to high temperatures and when cooled down again. At the high temperatures of reduction, the particles can sinter together, thus blocking access to the center lattices from incoming oxygen. As oxygen cannot travel inside, only the outer layer of the mass can be reduced. Adding iron oxide breaks the lattice structure of the manganese oxide due to size differences which allows the oxygen to reach far within the lattice and oxidize the whole mass [27].

While $10 \%$ has the best initial re-oxidation conversion, and the thermal storage capacity decreases with increasing $\mathrm{Fe}_{2} \mathrm{O}_{3}$ fractions, when the cycles are performed upwards to 500 times, the molecular structure begins to change and a total weight reduction of $3.4 \%$ can be attained. This improves the energy density of the material by packing the same amount of heat into a smaller mass. Interestingly, compounds with higher iron oxide compositions can reach this reduction faster. After optimizing the system with these two parameters into account (reoxidation and energy density), $15 \%$ was found to be best for the long-term recyclability of the storage system [27] (Figure 15). 


\subsubsection{Reactor Setup}

After considering a fixed bed, General Atomics, developing this cycle together with the DLR, thought it best to install a rotary kiln [37]. Given that the reaction proceeds spontaneously at high temperatures and that the only reactant for discharge is oxygen, there is no need to store reactants: air can be used to provide the oxygen required. Hence, the brunt of the system complexities is centered on the rotary kiln.

At first glance the kiln seems simple enough. There is no movement of solids: the metal oxide stays in the kiln when heated and the only exit stream from the reactor is the oxygen gas evolved which is easily removed (or stored, if it is cost-efficient to do so). Likewise, when the system needs to be discharged, air is streamed into the kiln where it reacts with the oxidized manganese oxide and heat is evolved. The air itself serves as the heat transfer fluid - as it leaves the kiln it will exchange heat with water to drive a Rankine cycle.

General Atomics mentions the limitations to throughput by only being able to store as much energy as is packed into the reactor.

\subsubsection{Charge - Reduction of $\mathbf{M n}_{2} \mathbf{O}_{3}$}

To initiate the cycle, ambient-stored $\mathrm{Mn}_{2} \mathrm{O}_{3}$ is placed within the rotating kiln and exposed to concentrated sunlight. This reaction will only be spontaneous at high temperatures: the equilibrium temperature for this reaction at ambient pressure is close to $950^{\circ} \mathrm{C}$. When undergoing reduction, this can rise to $1100^{\circ} \mathrm{C}$ (see equation 15).

In each $\mathrm{Mn}_{3} \mathrm{O}_{4}$ molecule, one of the manganese ions has been reduced from a $\mathrm{Mn}$ (III) to a Mn(II) ion; conversely, oxygen has been oxidized and formed a diatomic oxygen gas molecule. This reaction, due to the high temperatures, can possibly sinter the molecules together, impeding oxygen passage into the lattice for oxidation. This is prevented by the iron oxide ions which disorder the lattice creating gaps large enough for oxygen to pass.

$\mathrm{Mn}_{3} \mathrm{O}_{4}$ will stay in the kiln and the oxygen will leave. The sensible heat of both these substances should not be wasted since, at $950-1100^{\circ} \mathrm{C}$, they can easily be used to preheat the air for oxidation or to accumulate steam in the Rankine cycle. 


\subsubsection{Discharge - Oxidation of $\mathrm{Mn}_{3} \mathrm{O}_{4}$}

To discharge the storage system, the energy evolved when $\mathrm{Mn}_{3} \mathrm{O}_{4}$ is reacted with oxygen will have to be carried out by the same heat transfer fluid which provided the oxygen in the first place: air. Air is pumped into the kiln and as the $\mathrm{Mn}_{2} \mathrm{O}_{3}$ reacts into $\mathrm{Mn}_{3} \mathrm{O}_{4}$, the oxidized manganese oxide will increase its temperature but so will the gases around it. The magnitude of this temperature increase in the gas is dependent on its residence time in the kiln. Equilibrium temperature, as stated, is $900^{\circ} \mathrm{C}$ on average - as reduction could potentially go higher to $1100^{\circ} \mathrm{C}$, this allows oxidation a range of operation from $700-900^{\circ} \mathrm{C}$. Given the ease of sourcing air, it is not necessary to recycle it; in fact, this would only lengthen the conversion process. For $10 \%$ iron oxide doping, the re-oxidation in subsequent cycles could be up to $100 \%$; albeit, with $15 \%$ iron oxide, this value can drop to the $90-93 \%$ range.

\subsubsection{Conclusions}

The manganese oxide cycles are very easy and straight forward from an operability point of view: both reactions occur at roughly the same temperature and the reaction is run depending on whether sunlight is heating the reactor or if gas is coursing through it. The heat evolved, which is absorbed by the HTF, air, is high enough (at $900-1100^{\circ} \mathrm{C}$ ) to power a Ranking cycle through a heat exchanger further downstream. The chemistry of the reaction will still need work. Reoxidations are still not perfect even with iron oxide doping and they stabilize, at best, at $90 \%$ after numerous cycles. Last, while the rest of the cycle is relatively problem-free, the rotary kiln is still in basic levels of experimentation. The fact that this system does not employ water in any way, just air, makes it ideal for desert climates where all that would be needed to run the discharge would be an air compressor.

\section{Perovskite-form structures}

\subsection{Introduction}

Perovskites refers to class of compounds which have the same type of crystal structure as $\mathrm{CaTiO}_{3}$. Whilst being well known, perovskites have not been extensively researched for their thermal storage potential until very recently. Some experimentation had been done in the 70 s but it is only now that heat storage technologies are being commercially developed that they have resurged as a promising technology. 
The applicability of perovskites as energy storage media does not come from its chemical formula, in fact, it would be incorrect to claim that perovskites themselves are being experimented upon. What is useful about the perovskite is its structure: a lattice of a transition metal bound on all sides by oxygen forming an octahedral arrangement which is, in itself, in a larger cube lattice of a larger metal [38].

Consider the following formula as a template for perovskite structures: $\mathrm{ABX}_{3}$, with the structure shown in Figure 16. In this diagram, A, a cation, is represented by the big green spheres, B, another cation, by the blue ones and, finally, $\mathrm{O}$, the red oxygen circles, represents the anion.

What is special about this structure is that the cations are easily replaced by similar elements [40], and so the compound presents a wide array of possible chemical behaviors while keeping a similar structure. While keeping this structure as well, perovskite is mostly immune to a malaise that catalysts exposed to such high temperatures fall to sintering.

The constant structure, the porosity for oxygen transport and the ease with which it frees and occupies sites makes it a workable catalyst for Hydrogen gas production via solar means.

\subsection{Perovskite hydrogen production chemistry}

In industrial production of hydrogen gas, the preferred method to obtain the hydrogen in its desired form is through water splitting: this can be done by applying an electric charge (electrolysis, as shown in the sulfur cycle), through chemical reactions (as shown through the metal oxide reactions), and, last, using high enough temperatures to break apart the bonds (thermolysis). This last form, thermal degradation, is aided by the introduction of perovskites into the system.

There are numerous ways in which the perovskites can be utilized to the effect of yielding oxygen but a few factors are common: first, the cycle will necessitate large temperatures for reduction; second, the reaction is driven by, and enhanced by, large values for oxygen deficiency $(\Delta \delta)$; last, the catalyst array needs to be "activated" before it reaches a stable, high level of hydrogen gas production.

The perovskite hydrogen evolution mechanism employs vacant oxygen sites throughout the perovskite structure and uses these sites in alternating oxidation-reduction reactions [41]. 


\subsubsection{Reduction}

The compound is reduced by exposing it to heat (endothermic reaction) provided by solar radiation and releases oxygen gas:

$$
A_{x} B_{y} \mathbf{O}_{3 z}+\Delta H_{r x n} \rightarrow A_{x} B_{y} \mathbf{O}_{3 z-2}+\mathbf{O}_{2}
$$

(Equation 16)

If the system employs natural gas for hydrogen production, $\mathrm{CH}_{4}$ will be decomposed into $\mathrm{CO}_{2}$ and $\mathrm{H}_{2} \mathrm{O}$ :

$$
\mathrm{A}_{\mathrm{x}} \mathrm{B}_{\mathrm{y}} \mathrm{O}_{3 \mathrm{z}}+\mathrm{CH}_{4}+\Delta \mathrm{H}_{\mathrm{rxn}} \rightarrow \mathrm{A}_{\mathrm{x}} \mathrm{B}_{\mathrm{y}} \mathrm{O}_{3 \mathrm{z}-4}+\mathrm{CO}_{2}+2 \mathrm{H}_{2} \mathrm{O}
$$

(Equation 17)

Both these processes liberate the now-vacant oxygen sites throughout the structure.

\subsubsection{Oxidation}

In the following reaction, the water molecules, either from the feed or the ones newly created by the oxidation of natural gas, are submitted to even higher temperatures. Normally, to spontaneously thermally degrade, water would require a temperature of $4037^{\circ} \mathrm{C}$ [42] which is unrealistic for a successful commercial application of this technology. By using the perovskite catalyst, this requirement is reduced substantially. The plethora of perovskite-structure combinations which have been tested tend to show good results at working temperatures of around $900-1100^{\circ} \mathrm{C}$ [43]. The oxygen in the water binds to the vacant site in the perovskite lattice and breaks free from the hydrogen which forms a diatomic molecule: hydrogen gas. It has been shown that the "water-splitting reaction rate is proportional to the concentration of oxygen vacancies" [42].

$$
A_{x} B_{y} \mathbf{O}_{3 z-2}+2 H_{2} \mathbf{O}+\Delta H_{r x n} \rightarrow A_{x} B_{y} \mathbf{O}_{3 z}+2 H_{2}
$$

(Equation 18)

The reduction step also showcases one of the unique properties of the perovskite structures. Catalysts which are cycled at high temperatures such as those required by the reduction step tend to sinter and form a coating on the surface of the catalyst which prevents oxygen from entering the molecule and so disrupts the cycle. By keeping a constant structure regardless of the vacant or occupied oxygen sites, perovskite structures allow for oxygen to flow between the lattice bonds and reach the active sites. Small scale tests have shown no significant degradation 
in the perovskite structures after 80 cycles - this is still a long distance away from the 500 cycles commonly required for commercial readiness but it does comply with the full scope of the experiment [44].

\subsubsection{Discharging}

The energy is stored as hydrogen gas. Methods to optimize the evolution of hydrogen will be discussed further along. The hydrogen gas is combusted in the presence of either air or, more efficiently, pure oxygen in an optimized stoichiometric ratio which has its starting point in the following reaction:

$$
2 \mathrm{H}_{2(\mathrm{~g})}+\mathbf{O}_{2(\mathrm{~g})} \rightarrow 2 \mathrm{H}_{2} \mathbf{O}_{(g)}+\Delta \mathrm{H}_{\mathrm{rxn}} \quad \Delta \mathrm{H}_{\mathrm{rxn}}=-241.8 \mathrm{~kJ} \mathrm{kmol}^{-1}
$$

(Equation 19)

It is this heat which is used then to power a Rankine cycle to produce energy. Storing hydrogen as a thermal energy storage method can be cumbersome because the hydrogen gas must be compressed and safely monitored: leaks can be undetectable and explosive. Perovskite structures, then, in their current form and development, seem more poised as a method for commercial hydrogen generation than they are for energy storage for renewable power plants.

\subsection{Reactors}

While there are currently no commercial reactors operating with perovskite catalysts and powered by solar reactors, there are prototypes already designed which are gaining traction. Perovskite reactors have had a more difficult transition from the chemistry theory to the mechanical application. In large part that is because the compounds are still being experimented on, but it also denotes some technical limitations. Being a solid medium that needs to undergo two different temperatures for the oxidation and reduction steps, the construction is not as simple as the sulfur cycle (two different reactors). The same structure needs to undergo an increasing temperature profile, and then start again from the lower end, in order for it to be cyclic. With this in mind, it is unreasonable to consider a cyclic focus of the heliostats in order to match the required temperatures: the losses in energy and mechanical degradation from moving such large mirrors so often would decimate the energy profit.

Some prototypes have been created and they attempt radically different ways to tackle these problems. 


\subsubsection{Sandia packed particle bed reactor}

The Sandia Laboratories in the United States have devised a reactor which makes clever use of gravity and simple machines to overcome the temperature gradient problem [45]. The base of the reactor is a tank which holds the perovskite-structure pellets and it is fed a stream of reactant, e.g. water. The tank is kept at the oxidation temperature $\left(1000^{\circ} \mathrm{C}\right)$ and the oxidized particles leave the bottom tank together with the oxidation products (e.g. oxygen gas). These particles are transported to the top of the rig via a rotating screw. At the top of the reactor the radiation, conveyed to the setup via a beam-down system, is at its strongest (up to $1500^{\circ} \mathrm{C}$, optimized at $1350^{\circ} \mathrm{C}$ [44]) so the reduction process occurs at the top of the column. The reacted particles then drop down to the holding tank via a central hollow shaft and the process starts again.

The obvious setbacks to this machinery relate to the high number and dependability on moving parts as well as a difficulty keeping the temperature profile as desired without the help of a temperature control system. All of these involve extra inputs of energy or heating/cooling which subtract from the ability of the system to be efficient in terms of its overall energy use. In fact, despite exhibiting strong kinetic performances and a strong sunlight conversion efficiency, the overall thermal efficiency for the whole system is still substantially below commercial standards [42].

\subsubsection{Membrane reactors}

The big problem with perovskite redox reactors, as mentioned, is the need for a temperature change in the same material. Current investigations are attempting to devise a method by which the reaction can take place isothermally which would greatly remove the technical difficulties and operation costs of having two heating stages.

A perovskite membrane reactor takes a dried and powdered sample of the perovskite $\mathrm{La}_{0.3} \mathrm{Se}_{0.7} \mathrm{FeO}_{\delta}$ which is rolled and pressed down, and finally sintered at $1300^{\circ} \mathrm{C}$ [42]. Thin wafers of $3 \mathrm{~mm}$ thickness are cut in order to create the membrane. The membrane must first be activated before it can begin to split water. The principle behind this follows that for the oxidation to occur, the incoming vapor stream must react with oxygen vacancies in the perovskite lattice so as to break apart the water molecules: the oxygen must be pulled into the structure in order to fill the voids and, in so doing, liberate the Hydrogen gas. Therefore, the membrane must be first activated by reacting it with a reducing element such as methane or carbon monoxide. This can also be a reducing element throughout the reaction and carbon 
monoxide has proven to almost triple $(2.7 x)$ the amount of hydrogen produced [41]. Nonetheless, in the interests of an environmentally sound operation, carbon-based reducing agents can be forfeited in favor of unforced reduction by the recombination of oxygen gas.

The system is taken to, and kept, at a steady temperature of $860^{\circ} \mathrm{C}$, at ambient pressure, and under helium atmosphere in order to prevent side reactions. The reaction is kept in operation due to the flux of vacant oxygen spaces from the second compartment of the membrane, where the reduction and oxygen gas evolution takes place, towards the first compartment where the water is oxidized and split. The oxygen vacancies, resulting from the formation of oxygen gas from two ions contained in the vacancies, travel through the membrane and, upon reaching the first compartment, are able to provide an active site for the splitting of the water molecules and the capture of two more oxygen ions; these will, in turn, travel towards the membrane face at compartment two and restart the cycle.

The addition of a reducing agent in compartment two would result in higher hydrogen gas evolution due to the forced vacation of the oxygen sites as a result of shifting the equilibrium of the following reaction:

$$
o_{o}+C X \rightarrow C X O+V_{o}+2 e^{-}
$$

where $V_{o}$ is an oxygen vacancy; and, $\mathrm{CX}$, a carbon-based reducing agent.

During the initial pulse, when the perovskite membrane surface is at a high concentration of vacancies, a remarkable conversion of over $80 \%$ was attained. This value drops during subsequent pulses and steadies to below $10 \%$ per pulse (Figure 19).

A constant removal of oxygen gas would have the effect of freeing more vacancies and thus improving the yield of the membrane, as shown previously with the organic reducing agent. This proves that the main driving force for the membrane reactor is the oxygen deficiency of the material, represented by $\Delta \delta$ [42]. 


\subsection{Hydrogen gas yield optimization}

\subsubsection{Molecular Composition}

The reaction kinetics of the perovskite structure can be improved by micromanaging the molecules in the lattice. The introduction of other metals in small doses, common technique known as "doping" the lattice, allows the enhancement of certain desired properties without changing the structure: these new metals simply take some of the sites of the other elements in the A or B sites. The metals are very much interchangeable but the relative sizes must be maintained in order for the lattice to remain stable. The varied makeup of the perovskite structures resulting from this process yields some daunting chemical formulas, for instance:

$$
S r_{0.4} L a_{0.6} M n_{0.6} A l_{0.4} O_{3-\delta} \quad \text { (Equation 21) }
$$

The molecular formula above is the composition of SLMA-1. The basic structure of $\mathrm{LaAlO}_{3}$ has been doped with Manganese (II, III \& IV) in the B-site and Strontium (II) in the A site so as to make the alloy more tolerant to oxygen non-stoichiometry and further redox activity [41].

It is not only the kinetics but also the formation energies which can be altered. For energy storage systems, higher formation energies are desired given that these represent a smaller volume of storage material for the same amount of power delivered so looking for ways to maximize the formation energies of perovskites is imperative (Figure 20).

Perovskites have been tested with regards to the elements present in the A and the B site. It was found that for a given cation at B, identical oxidation states of the cations in A do not have much of an effect in the formation energy of the system. If the oxidation states are, indeed, different, then the changes in the formation energy are ordered and predictable [46].

If, albeit, the element at $\mathrm{A}$ is kept constant and $\mathrm{B}$ is modified, then the formation energies also vary linearly with the increasing atomic number of B along the same period. The slopes of these linear relations are determined by the oxidation number of the element at A (Figure 10). 


\subsubsection{Reactor Operation}

Besides the perovskite preparation, there are methods to be employed with regards to the way the reactor is run that can significantly improve the efficiency of the system both in terms of yield and in reducing utilities.

Principally, the equilibrium should favor a higher yield: pressures should be kept at ambient pressure and the $\mathrm{H}_{2}$ and $\mathrm{O}_{2}$ products should be continuously removed from the system to shift the equilibrium towards the products. A tried and tested benchmark is to keep the ratio between $\mathrm{H}_{2} \mathrm{O}$ and $\mathrm{H}_{2}$ higher than 100 [41].

Additionally, the hydrogen gas yield has been found to increase when the regeneration time, the time spent oxidizing the compound, is meaningfully increased beyond what is theoretically predicted. Empirical trials on the sol-gel composed of manganese ferrite $\left(\mathrm{Mn}_{0.74} \mathrm{Fe}_{1.26} \mathrm{O}_{3}\right)$ concluded that by increasing the oxidation time from 2 to 4 hours, though oxygen yield rose by $12.45 \%$ [43].

Heat recovery in this system takes a special priority: it is no longer a method to reduce utility costs in the system - it becomes a necessity for the competitive operation of this reactor due to the hefty thermal inefficiency of the rig. One of the largest contributors to these losses is the large temperature difference needed between the oxidation and reduction temperatures. To be able to diminish the inefficiency of the system to future commercially viable levels, this heat must be recovered.

The Sandia laboratory has begun to experiment with recuperators in light of this and their first results show a very strong dependence of the total efficiency of the system on the efficiency of the recuperator itself [44]. An efficient recuperator (over $80 \%$ heat recovery) can triple $(32.2 \%$ vs $10.7 \%$ ) the solar efficiency of a system with no recuperator at all (Figure 21).

Last, the physical construction of perovskite structures, while it hasn't proven to degrade throughout operation, can still be enhanced. More complex chemical synthesis methods have been proposed for the construction of the pervoskite lattices: thermal ammonolysis, exposure of the compound to a high-temperature flow of $\mathrm{NH}_{3}$, has been used to convert the perovskite $\mathrm{La}_{2} \mathrm{Ti}_{2} \mathrm{O}_{7}$ into a $\mathrm{LaTiO}_{2} \mathrm{~N}$ oxynitride. Testing on the hydrogen gas evolution as a factor of the ammonolysis time showcased a strong correlation between the time spent ammonolysing the compound and its hydrogen yield [47]. 
As mentioned, the possibility of perovskite membranes as a reactor medium is a promising way of addressing both the temperature gradient problem and the limitations to surface area. By confining the oxidation stage to one face of the membrane and the hydrogen producing reduction on the other, "the created oxygen ion and vacancy gradients form the driving forces for transmembrane diffusion. In this way a constant vacancy rich (and thus active) membrane surface for water dissociation may be provided." Previous experiments have shown that the initial pulse of water, acting on a freshly regenerated perovskite lattice, can achieve astounding conversions approaching 70\%; this value degrades rapidly as subsequent pulses follow and the oxygen vacancies are filled. If the membrane reactors can upkeep the conditions of the newlyregenerated structure, then these high conversion values could, in theory, be sustained [48].

\subsection{Comparison to other catalysts: $\mathrm{Ceria}\left(\mathrm{CeO}_{2}\right)$}

Ceria was the first catalyst to be analyzed for this type of reactor (PPBR) by Sandia and, initially, its reactor was designed around ceria [41]. It has commonly been the ubiquitous catalyst for water splitting cycles by chemical means, outperforming the more frugal ferrites. When compared to the perovskite structures, using ceria involved operating at higher temperatures all around: The oxidation stage was planned at $1100^{\circ} \mathrm{C}$ and the reduction, at $1550^{\circ} \mathrm{C}$. Ferrites reduced at a closer $1400^{\circ} \mathrm{C}$ yet still higher than the SLMA perovskites. Ceria is durable and an efficient catalyst in terms of the speed of reaction it achieves; unfortunately, it is also composed of cerium which is a rare metal: ergo, expensive. Its biggest setback, however, proved to be its low reduction capacity - Ceria presents difficulties in resetting its hydrogen production cycle.

Finally, when compared to the SLMA perovskites, ceria was shown to be outmatched. On average, the SLMA perovskites produced nine times the amount of hydrogen than the ceria was able to [41]. Together with the fact that due to its versatility in composition and its common materials, perovskites are cheaper to obtain, ceria was finally discarded as a viable choice in this reactor. Notwithstanding, due to its trajectory and wide use, it is still often compared to as a benchmark catalyst.

\subsection{Conclusions}

The perovskite structures as catalysts for hydrogen production are still at an early stage of development. Only a few reactors have been tested and the entirety of them only at a laboratory scale. Its benefits are evidenced by the results: perovskites facilitate oxygen diffusion without deforming and so they can operate at high temperatures necessary for a catalysed water-splitting 
reaction. Furthermore, they have eclipsed the production capacity of previous catalysts like Ceria by tripling thrice the amount of hydrogen produced in similar circumstances and even at, on average, $100^{\circ} \mathrm{C}$ less of operation. Last, they are cheap, malleable and readily available.

They are best suited for desert operations because even if they require water to operate, it has been shown that the water can be sourced by operating absorption chillers, to extract the water from the air, using the waste heat from the reactor itself [10].

Their major setback, nonetheless, is the efficiency. At a maximum efficiency of $32.2 \%$ and a yearly average of $25 \%$ it is severely lagging behind the Department of Energy's solar-to-heat target of $65 \%$. In the current reactor construction, there are several mechanical parts which could be an avenue for wasted energy and technical malfunctions. In parallel, the membrane reactors are even less developed and suffer from a steady rate of less than $10 \%$ which is too wasteful. Efforts to improve the reaction by adding natural gas or carbon monoxide as a stronger reducing agent become contradictory to the self-touted nature of the project as selfsufficient and free from the volatilities of fossil fuels.

Current objectives for developers focus on the heat recovery from the system and rig itself, minding that a higher energy recovery efficiency translates to a higher overall efficiency; finding cheaper materials for the perovskites, hopefully bypassing any rare metal; carrying out the reaction at higher pressures to encourage gas formation; and, developing a method of constant and efficient gas removal in order to shift the equilibrium towards higher levels of $\mathrm{H}_{2}$ production.

\section{Closing Remarks}

The cycles shown here are all promising in their strengths yet none seems to be complete enough to become ubiquitous in any field (Table 1). Usually, what is noteworthy in one, is exactly what another otherwise viable storage is lacking. The sulfur based cycles, like the perovskites, are geographically limited by the incorporation of water in the cycle. To a lesser extent, so is the calcium hydroxide cycle.

Others are held back by infant technologies: the perovskite membrane is lauded by studies focusing on fluidized beds with perovskites due to the isothermal operation and the simplicity of not having to transport solids. The membrane has only been proven so far at a laboratory scale and the applications were it to be scaled up to have not been tested yet. The same can be said for 
the rotary kilns. A DLR prototype for a closed kiln has been tested at a pilot scale with a single heliostat and has shown good results notwithstanding the high capital costs. But for this kiln to be converted into a continuous system, it would have to be designed based on unproven technology outside the laboratory scale.

Last, when the technology does exist, it might not be fit to handle the specified cycle. In the sulfur cycles, a combined cycle requires a Brayton turbine to be exposed to sulfur dioxide gases which will become highly corrosive if any water is present in the system. Likewise, the doping being performed to improve the desired properties of perovskites makes their toxicity unpredictable: just like they might improve the formation of vacant sites, it could also have unexpected influences on the $\mathrm{pH}$ of the system and could become corrosive.

As in any new technology being developed, the ideal is highly prized. With so many different reactions it is easy to be tempted to take the simpler, risk free alternatives. The unfortunate outcome of this is that the complex systems are not developed as ambitiously afterwards. So with all these previous factors considered, this review concludes that the calcium carbonate is the cycle with most experimentation behind it to infer that it could be viable and should thus be attempted at a research plant scale once a reactivation cycle can be designed. Further along, the manganese oxide cycle, while less developed, is fundamental enough to be a suitable application for desert climates over the rest of the water-frugal or even water-avoiding cycles. It has proven to be cyclable up to 1100 times while only losing $10 \%$ : this is truthfully grand when it comes to storage cycle performance in the long term and it makes up for the low heat evolved by the reaction compared to the rest.

\section{Acknowledgements}

The work was partially funded by the Spanish government (project ENE2011-22722). The authors would also like to thank the Catalan Government for the quality accreditation given to their research group GREA (2014 SGR 123) and DIOPMA (2014 SGR 1543). The research leading to these results has received funding from the European Union's Seventh Framework Programme (FP7/2007-2013) under grant agreement nº PIRSES-GA-2013-610692 (INNOSTORAGE). 


\section{References}

1. Parfomak PW. Energy Storage for Power Grids and Electric Transporation: A Technology Assessment. Congressional Research Service, 2012.

2. Gil A, Medrano M, Martorell I, Lázaro A, Dolado P, Zalba B, Cabeza LF. State of the art on high temperature thermal storage for power generation. Part 1 - Concepts, materials and modelization. Renewable and Sustainable Energy Reviews, 2010:14;31-55.

3. www.abengoasolar.com. Accessed last time July 2014.

4. Fernandez AI, Martinez M, Segarra M, Martorell I, Cabeza LF. Selection of materials with potential in sensible thermal energy storage. Solar Energy Materials \& Solar Cells 2010:94;1723-1729

5. Tamme R. IEA ECES Annex 19: Optimised Industrial Process Heat and Power Generation with Thermal Energy Storage. Final report, 2010.

6. IEA-ETSAP, IRENA. Thermal Energy Storage- Technology Brief, 2013.

7. Cot-Gores J, Castell A, Cabeza LF. Thermochemical energy storage and conversion: A-state-of -the art review of the experimental research under practical conditions. Renewable and Sustianable Reviews, 2012:16;5207-5224.

8. A. Wörner, German Aerospace Center- 7th Framwork Programme, 2014. Available at: http://www.tcs-power.eu/reports-publications/conferences.html. Accessed last time July 2014.

9. R. Project, Seventh Framework Programme, 2014. Available at: http://www.restructure-project.org/. Accessed last time July 2014.

10. Sattler C, Wörner A. «Thermochemical Energy Storage: Overview on German, and European R\&D Programs and the work carried out at the German Aerospace Center DLR. Deutschen Zentrum für Luft-und Raumfahrt (DLR), 2013.

11. U.S. Department of Energy, SunShot Initiative, 20 June 2013. Available at: http://www1.eere.energy.gov/solar/sunshot/about.html. Accessed last time July 2014.

12. General Atomics, DLR. Sulfur Based Thermochemical Heat Storage for Base load Concentrating Power, 2011.

13. Roeb M. Sulfur and ferrite-based thermochemical cycles for water splitting. SFERA Winter School. Solar Fuels \& Materials, Zurich, Switzerland, 2011.

14. Sattler C. Solar Fuels: Overview of the Work Carried Out at the German Aerospace Center. Solar Fuels, Niigata University, Japan, 2012.

15. Wong B, Brown L, Buckingham R, Thomey D, Roeb M, Sattler C. Sulfur Based Thermochemical Energy Storage for Concentrated Solar Power. SolarPACES, Marrakech, Morocco, 2012.

16. Thomey D, Lennartz F, Schöllgen D, de Oliveira L, Säck J.-P., Roeb M, Sattler C. Development and Test of a Solar Decomposer of Sulphuric Acid for Thermochemical Hydrogen Production. ICPH2 $11^{\text {th }}$ International Conference on Hydrogen Production, Thessaloniki, Greece, 2011.

17. General Atomics. Thermochemical Heat Storage for Concentrated Solar Power Based on Multivalent Metal Oxides. CSP Program Review. Award Number: DE-FG-36-08GO18145, 2011.

18. Air Liquide. Air Liquide Gas Encyclopedia. Available at: http://encyclopedia.airliquide.com/Encyclopedia.asp?GasID=27. Accessed last time July 2014. Accessed last time July 2014.

19. DKL Engineering, Inc. Sulphuric Acid on the Web. Available at: http://www.sulphuricacid.com/techmanual/Properties/properties_sulphur.htm. Accessed last time July 2014.

20. Smitkova M, Janicek F. Comparison of thermo-chemical water splitting cycles. Power System Operation and Control, AT\&P journal PLUS2, 2008;41-43.

21. IEA/HIA Task 25. Hybrid Sulfur Cycle. Available at: http://ieahia.org/pdfs/Task25/Hybrid-SulfurCycle.pdf. Accessed last time July 2014.

22. AuYeung N. Hydrogen Production via a Sulfur-Sulfur Thermochemical Water-Splitting Cycle. PhD Thesis, Oregon State University, USA, 2011.

23. Le Duigou A, Borgard JM, Larousse B, Doizi D, Allen R, Ewan BC, Priestman GH, Elder R, Devonshire R, Ramos V, Cerri G, Salvini C, Giovannelli A, De Maria G, Corgnale C, Brutti S, Roeb M, Noglik A, Rietbrock PM, Mohr S, de Oliveira L, Monnerie N, Schmitz M, Sattler C, Orden Martinez A, de Lorenzo Manzano D, Cedillo Rojas J, Dechelotte S. HYTHEC: An EC funded search 
for a long term massive hydrogen production route using solar and nuclear technologies.

International Journal of Hydrogen Energy 2007:32;1516-152.

24. Möller S, Roeb M, Sattler C. Solar Thermal Hydrogen Production via Reforming and ThermoChemical-Cycles. ForschungsVerbund Sonnenenergie Workshop 2007, Ulm, Germany, 2007.

25. United States Department of Energy. Nuclear Hydrogen R\&D Plan, 2004.

26. EXTOXNET - Extension Toxicology Network. Cornell University, USA, 1994. Available at: http://pmep.cce.cornell.edu/profiles/extoxnet/pyrethrins-ziram/sulfur-ext.html. Accessed last time July 2014.

27. United States Department of Energy Project Staff. Thermochemical Heat Storage for Concentrated Solar Power: Thermochemical System Reactor Design for Thermal Energy Storage. U.S. Department of Energy, USA, 2011.

28. Edwards SE, Materić V. Calcium looping in solar power generation plants. Solar Energy 2012:86;2494-2503.

29. Meier A, Bonaldi E, Cella GM, Lipinski W, Wuillemin D. Solar chemical reactor technology for industrial production of lime. Solar Energy 2006:80;1355-1362.

30. Neises M, Tescari S, de Oliveira L, Roeb M, Sattler C, Wong B. Solar-heated rotary kiln for thermochemical energy storage. Solar Energy 2012:86;3040-3048.

31. Wieckert C, A $300 \mathrm{~kW}$ Solar Chemical Pilot Plant for the Carbothermic Production of Zinc. Journal of Solar Energy Engineering 2007:129;190-197.

32. Wörner A, Linder M. Thermochemical Storage of Heat. Achema 2012, Frankfurt, Germany, 2012.

33. Schaube F, Wörner A, Müller-Steinhagen H. High Temperature Heat Storage Using Gas-Solid Reactions. Effstock 2009, Stockholm, Sweden, 2009.

34. Arpa-e Energy. Thermochemical Storage Breakout. United States Department of Energy, USA.

35. Felderhoff M, Urbanczyk R, Peil S. Thermochemical Heat Storage for High Temperature Applications - A Review. Green, 2013:3;113-123.

36. Bauerle G, Chung D, Ervin G, Guon J. Storage of solar energy be inorganic oxide/hydroxides. Ed. Springer, 1976.

37. Wong B. Lessons Learned: Developing Thermochemical Cycles for Solar Heat Storage Applications. IFT P2013-001 Workshop on TES for CSP, 2013.

38. Borowski M. Perovskite: Structure, Properties and Use. Nova Science Publisher, New York, 2011.

39. Navrostky A. Energetics and Crystal Chemical Systematics among Ilmenite, Lithium Niobate, and Perovskite Structures. Chem. Mater. 1998:10;2787-2793.

40. Peña MA, Fierro JL. Chemical Structures and Performance of Perovskite Oxides. Chem. Rev. 2001:101;1981-2017.

41. McDaniel AH, Miller EC, Arifin D, Ambrosini A, Coker EN, O'Hayre R, Chueh WC, Tong J. Sr-and Mn-doped $\mathrm{LaAlO}_{(3-\delta)}$ for solar thermochemical $\mathrm{H}_{2}$ and $\mathrm{CO}$ production. Energy Environ. Sci. 2013:6;2424-2428.

42. Evdou A, Nalbandian L, Zaspalis VT. Perovskite membrane reactor for continuous and isothermal redox hydrogen production from the dissociation of water. Journal of Membrane Science 2008:325;704-711.

43. Bhosale RR, Shende RV, Puszynski JA. Thermochemical water-splitting for $\mathrm{H}_{2}$ generation using solgel derived Mn-ferrite in a packed bed reactor. Int J Hydrogen En 2012:37;2924-2934.

44. McDaniel A, Ermanoski I. Solar Hydrogen Production with a Metal Oxide Based Thermochemical Cycle. Project ID: PD081, DOE Annual Merit Review, 2013.

45. Ermanoski I, McDaniel A, Siegel N. Solar Hydrogen Production with a Metal Oxide Based Thermochemical Cycle. Project ID: PD081, DOE Annual Merit Review, 2012.

46. Zeng Z, Calle-Vallejo F, Mogensen MB, Rossmeisl J. Generalized trends in the formation energies of perovskite oxides. Phys Chem Chem Phys 2013:20;7526-7533.

47. Maegli AE, Otal EH, Hisatomi T, Yoon S, Leroy CM, Schäuble N, Lu Y, Grätzel M, Weidenkaff A. Perovskite-type $\mathrm{LaTiO}_{2} \mathrm{~N}$ oxynitrides for solar water splitting: Influence of the synthesis conditions. Energy Procedia 2012:22;61-66.

48. Evdou A, Zaspalis V, Nalbandian L. $\mathrm{La}_{(1-x)} \mathrm{Sr}_{\mathrm{x}} \mathrm{MnO}_{(3-\delta)}$ perovskites as redox materials for the production of high purity hydrogen. Int J Hydrogen En 2008:33;5554-5562. 


\section{Figure captions}

Figure 1: Overview working pairs tested in prototypes under practical conditions [7]

Figure 2: Sulfur Storage Cycle Drafted by General Atomics [12]

Figure 3: Solar reactor at the DLR facilities in Köln, evaporator (right) and decomposer (left) [10]

Figure 4: Front and back view of an evaporator and decomposer [13]

Figure 5: Relationship between temperature of operation and conversion in a decomposer [14]

Figure 6: Process control \& instrumentation diagram for the disproportionation reactors in series

Figure 7: Process flow diagram for the sulfur cycle with direct \& indirect combined cycle generation

Figure 8: Block diagram for a hydrogen gas producing Westinghouse cycle [20]

Figure 9: Block diagram of the sulfur-iodine cycle [23]

Figure 10: Process flow diagram for the calcium carbonate energy storage cycle [28]

Figure 11: a) Meier continuous kiln diagram; b) prototype view [29]

Figure 12: Reaction diagram for $\mathrm{CaO} / \mathrm{Ca}(\mathrm{OH})_{2}$ cycle [31]

Figure 13: Indirect heating of a calcium hydroxide cycle [32]

Figure 14: Optimizing the equilibrium temperature with pressure [33]

Figure 15: Efficiency as a heat storage method vs. composition of iron oxide [27]

Figure 16: Perovskite Structure - A: Green, B: Blue, O: Red [39]

Figure 17: Sandia's packed particle bed reactor [45]

Figure 18: Perovskite membrane reactor [42]

Figure 19: Conversion of $\mathrm{H}_{2} \mathrm{O}$, total hydrogen gas production as a function of oxygen deficiency [42]

Figure 20: Formation energy trends for perovskite structures [46]

Figure 21: Recuperator efficiency and its effect on total solar efficiency [43]

Figure 22: Production of hydrogen in ceria vs. SLMA [41] 
Table 1. System parameters of the cycles studied.

\begin{tabular}{|c|c|c|c|c|c|}
\hline \multirow[t]{2}{*}{ Parameters } & \multirow[t]{2}{*}{ Sulphur based cycles } & \multicolumn{3}{|c|}{$\begin{array}{l}\text { Metal Oxide Redox cycles } \\
\end{array}$} & \multirow{2}{*}{$\begin{array}{l}\text { Perovskite-form } \\
\text { structures }\end{array}$} \\
\hline & & $\begin{array}{c}\text { Calcium carbonate } \\
\text { cycle }\end{array}$ & $\begin{array}{c}\text { Calcium hydroxide } \\
\text { cycle }\end{array}$ & $\begin{array}{c}\text { Manganese oxide } \\
\text { cycle }\end{array}$ & \\
\hline $\begin{array}{l}\text { Operation temperatures } \\
\left({ }^{\circ} \mathrm{C}\right)\end{array}$ & $\begin{array}{c}\text { Evaporation: } 400-500 \\
\text { Decomposition: } 850 \\
\text { Disproportionation: } 120-150\end{array}$ & $\begin{array}{l}\text { Calciner: } 900 \\
\text { Carbonator: } 875\end{array}$ & $\begin{array}{l}\text { Charging: 507-600 } \\
\text { Discharging: }<507- \\
\quad<600\end{array}$ & $\begin{array}{l}\text { Oxidation: } \approx 900 \\
\text { Reduction: } 900- \\
1100\end{array}$ & $\begin{array}{l}\text { Oxidation: } 1000 \\
\text { (PPBR) } \\
\text { Reduction: } 1350 \\
\text { (PPBR) } \\
\text { Isothermal: } 860^{\circ} \mathrm{C} \\
\text { (Membrane) }\end{array}$ \\
\hline Conversion $(\%)$ & n.a. & n.a. & n.a. & 90 & n.a. \\
\hline Thermal efficiency* $(\%)$ & $\approx 50$ & 42.8 & $\begin{array}{l}\text { From HTF: } 90-93 \% \\
\text { conversion }\end{array}$ & n.a. & $\begin{array}{c}\text { With Heat } \\
\text { Recovery: } 32.2\end{array}$ \\
\hline Type of cycle & $\begin{array}{l}\text { Rankine Cycle or Combined Cycle } \\
\text { from Superheated Sulphur Dioxide } \\
\text { and Air } \\
\text { Hydrogen-fuelled Rankine Cycle }\end{array}$ & $\begin{array}{l}\text { Air-based Brayton } \\
\text { Cycle }\end{array}$ & $\begin{array}{l}\text { Indirect heating. } \\
\text { Energy transferred } \\
\text { to and from the } \\
\text { plant's HTF }\end{array}$ & $\begin{array}{l}\text { High temperature } \\
\text { air as HTF driving a } \\
\text { Rankine cycle }\end{array}$ & $\begin{array}{l}\text { Hydrogen Storage } \\
\text { and Rankine } \\
\text { Generation Cycle } \\
\text { with Air or Oxygen } \\
\text { as a reactant }\end{array}$ \\
\hline Discharge conditions & $\begin{array}{l}\text { Sulphuric Acid and Elemental Sulphur } \\
\text { stored at ambient conditions }\end{array}$ & n.a. & $\begin{array}{c}\text { Increased pressure } \\
(\approx 2 \text { bar }) \text { and high } \\
\text { temperature Steam } \\
\left(\mathrm{T}_{\text {steam }} \geq 450^{\circ} \mathrm{C}\right) . \mathrm{CaO} \\
\text { should be prevented } \\
\text { from losing heat } \\
\left(\mathrm{T}_{\mathrm{CaO}} \approx 507-600^{\circ} \mathrm{C}\right)\end{array}$ & $\begin{array}{l}\text { Air at ambient } \\
\text { pressure and } \\
\quad \approx 900^{\circ} \mathrm{C}\end{array}$ & $\begin{array}{c}\text { Hydrogen } \\
\text { centralised delivery } \\
\text { at } 20 \text { bar, } 1000^{\circ} \mathrm{C} \\
(\mathrm{PPBR}) \\
\text { Hydrogen Produced } \\
\text { at ambient pressure, } \\
860^{\circ} \mathrm{C}\end{array}$ \\
\hline Energy density $\left(\mathrm{MJ} / \mathrm{m}^{3}\right)$ & n.a. & 4400 & 3000 & n.a. & n.a. \\
\hline $\begin{array}{l}\text { Levelised Cost of Energy } \\
(\$ / \mathrm{kWh})\end{array}$ & 0.081 & n.a. & n.a. & 0.18 & 0.09 \\
\hline
\end{tabular}

*Based on the heat supplied to the thermal storage unit 